\title{
Preparation and Antitumor Activity of Betulin Dipropionate and its Composites
}

\author{
Svetlana A. Kuznetsova ${ }^{1 \mathbb{D}}$, Tatyana P. Shakhtshneider ${ }^{2 \mathbb{D}}$, Mikhail A. Mikhailenko ${ }^{2 \mathbb{D}}$, \\ Yury N. Malyar 1,* (D), Anna S. Kichkailo ${ }^{3}$ (D), Valeri A. Drebushchak ${ }^{4}$, Boris N. Kuznetsov ${ }^{1(D)}$ \\ 1 Institute of Chemistry and Chemical Technology SB RAS, Federal Research Center "Krasnoyarsk Scientific Center SB \\ RAS", Akademgorodok, 50/24, Krasnoyarsk, 660036, Russia; kuznetssvetl@yandex.ru (S.A.K.); \\ 2 Institute of Solid State Chemistry and Mechanochemistry SB RAS, Kutateladze str., 18, Novosibirsk, 630128, Russia; \\ shah@solid.nsc.ru (T.P.S.); \\ 3 Krasnoyarsk State Medical University named after prof. V.F. Voyno-Yasenetsky, Partizana Zheleznyaka, 1, Krasnoyarsk, \\ 660022, Russia; annazamay@yandex.ru (A.S.K.); \\ 4 V.S. Sobolev Institute of Geology and Mineralogy SB RAS, pr. Ak. Koptyuga, 3, Novosibirsk, 630090, Russia; \\ dva@igm.nsc.ru (V.A.D.); \\ * Correspondence: yumalyar@gmail.com (Y.N.M.);
}

Scopus Author ID 55674311600

Received: 6.09.2021; Revised: 25.10.2021; Accepted: 28.10.2021; Published: 20.11.2021

Abstract: Betulin dipropionate is a natural compound with high cytotoxicity toward many cancer cells. The one-step synthesis directly from the birch bark without a separate betulin isolation stage was developed to obtain betulin dipropionate. Due to its composition, betulin dipropionate is a promising drug for treating a wide range of diseases. However, the poor water solubility of this compound has limited its applications. We prepared the composites of betulin dipropionate using two methods: ball milling of the mixtures of betulin dipropionate with synthetic and natural polymers, such as polyvinylpyrrolidone polyethylene glycol, fumed silica, arabinogalactan, and preparation of thin films with arabinogalactan by evaporating the aqueous solutions. These composites showed higher water solubility and improved antitumor properties against ascites carcinoma cells and human lung adenocarcinoma cells compared with the initial substance. Furthermore, the cell viability studies based on Annexin V and Propidium iodide probes confirmed the high proapoptotic effect of betulin dipropionate against cancer cells.

Keywords: betulin dipropionate; composites; polyvinylpyrrolidone; polyethylene glycol; fumed silica; arabinogalactan; mechanochemical synthesis; ball-milling; solubility; antitumor activity.

(C) 2021 by the authors. This article is an open-access article distributed under the terms and conditions of the Creative Commons Attribution (CC BY) license (https://creativecommons.org/licenses/by/4.0/).

\section{Introduction}

Betulin and its derivatives were found to possess unique pharmacological properties, including antitumor, antiviral, anti-inflammatory, and antiprotozoal activities [1-13]. The products based on betulin derivatives are already used as the major constituents of some drugs and dietary supplements [2,5]. The antitumor potential of betulin and its derivatives is particularly interesting [7-13]. It has been reported that betulin and its derivatives selectively affect a wide range of tumor cell lines both in vitro and in vivo have no cytotoxic effects on normal cells [7,11].

Betulin dipropionate (BDP), 3 $\beta, 28$-di- $O$-propionyl-lup-20(29)-lupene (1), is a complex ester of betulin and propionic acid (Figure 1). 


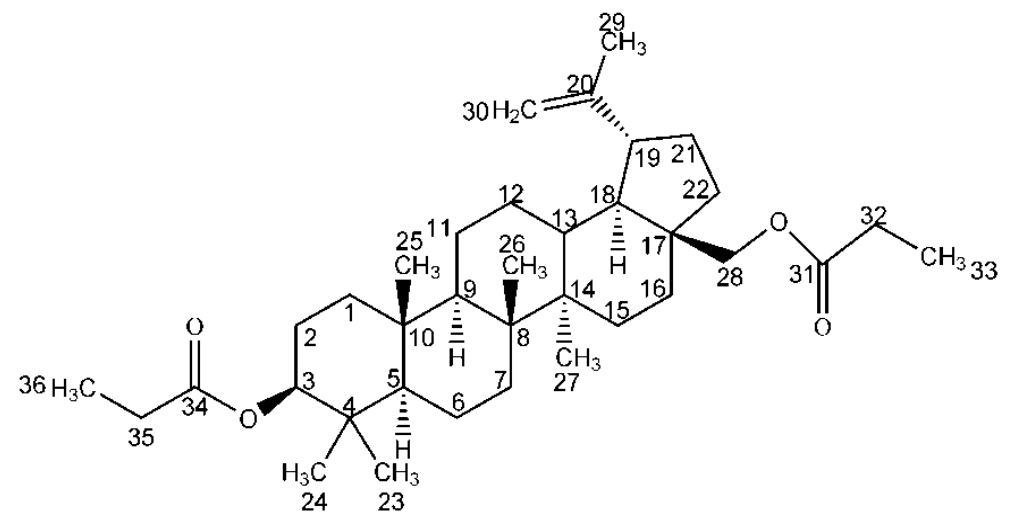

Figure 1. Molecular structure of betulin dipropionate.

Propionic acid, $\mathrm{C}_{2} \mathrm{H}_{5} \mathrm{COOH}$, (from Greek "protos" - the first, "pion" - fat) is named so because it is the acid with the smallest hydrocarbon chain, $\mathrm{H}\left(\mathrm{CH}_{2}\right)_{2} \mathrm{COOH}$, exhibiting the properties of fatty acids. Propionates were reported to protect the bone system from pathological destruction (osteoporosis) [14]; targeted delivery of propionate to the colon prevents weight gain in overweight adults [15]; propionate synthesized from lactate is the reason for increasing physical endurance and can be useful both for athletes and for people with a sedentary lifestyle, increasing their performance [16]. Propionic acid (in the form of propionates) is a metabolite of the intestinal microflora and exhibits antibacterial and antiviral properties $[17,18]$.

Due to the diverse pharmacological activity of both betulin and propionates, betulin dipropionate should be expected to exhibit a broader range of pharmacological properties than betulin and other triterpenoids. An additional advantage of applying betulin dipropionate over other betulin derivatives is the possibility of its simple one-step synthesis from birch bark in contrast to the multi-step syntheses of other betulin derivatives [19].

Despite the high potential prospects of using betulin dipropionate in pharmacy, there are practically no works in the literature devoted to the studies of its pharmacological activity. The current paper is a brief review and discussion of the results obtained by authors on onestep isolation of betulin dipropionate from birch bark, on the studies of its physicochemical properties and pharmacological activity, and the development of new composite materials based on betulin dipropionate.

Similar to the case of other betulin derivatives, in vitro and in vivo studies of betulin dipropionate are rather limited due to its poor solubility in water and low bioavailability. In our studies, we used mechanochemical methods to improve the solubility and bioavailability of betulin dipropionate.

Mechanochemical methods are widely used for drug modification, including drug amorphization, polymorphous transformations, solubilization via the preparation of solid dispersion systems (or composites) [20-22].

In our studies, synthetic and natural polymers and inorganic nano-systems were used as carriers to prepare composite materials by mechanochemical methods. In addition, the composites were prepared as water-soluble films using a physical or ball-milled mixture of precursor components. Schematic illustration of various drug delivery approaches for improving the solubility, and therapeutic efficacy of betulin dipropionate (BDP) is presented in Figure 2.

In the current paper, the results obtained for betulin dipropionate are compared with those obtained for betulin itself and another ester of betulin, betulin diacetate (BDA). 
The antitumor activity of the obtained materials against Ehrlich ascites adenocarcinoma cells and human lung adenocarcinoma cells is reviewed in this paper. The suggested mechanisms of the action of BDP in the treatment of cancer are discussed. Lung cancer is the most commonly diagnosed cancer ( $11.6 \%$ of the total cases), accounting for $18.4 \%$ of cancer deaths [23]. Therefore, the search for new preparations for its treatment is very important.

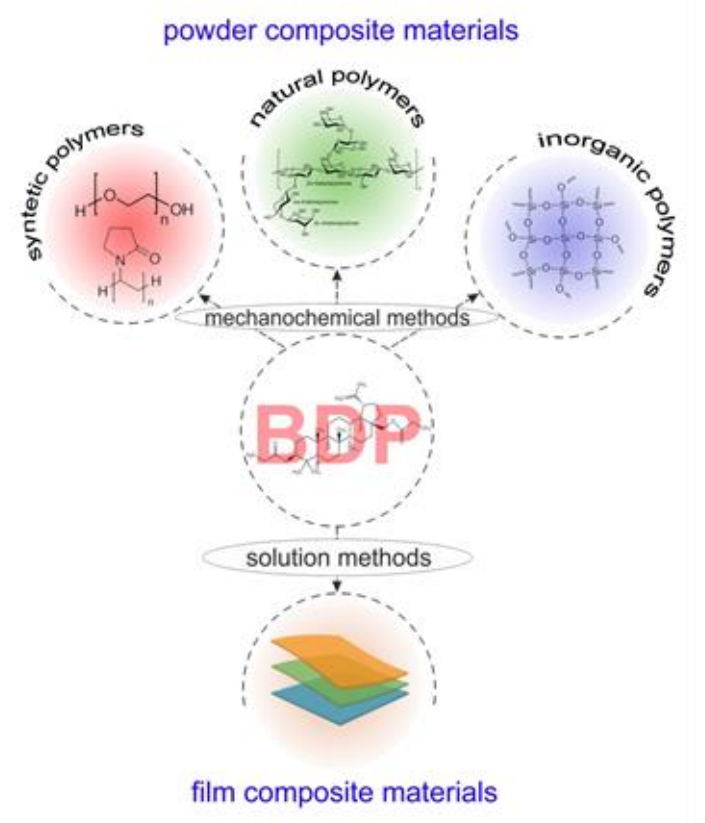

Figure 2. Schematic illustration of various drug delivery approaches for improving the solubility and therapeutic efficacy of BDP.

\section{Materials and Methods}

\subsection{Synthesis and purification of betulin dipropionate.}

Betulin dipropionate was synthesized in a round-bottom flask with a reflux condenser. The flask was loaded with birch bark crushed to a fraction of $2-5 \mathrm{~mm}$, then propionic acid was added, and the mixture was kept in an oil bath at a temperature of $120-130{ }^{\circ} \mathrm{C}$ for 8 hours. In a propionic acid medium, the reaction of betulin esterification into betulin dipropionate occurs together with the extraction of betulin from fractionated birch bark. Then the birch bark was filtered off, the solution was evaporated, and the resulting concentrate was poured into distilled water. The light gray precipitate was filtered off and dried in a desiccator. The product was recrystallized from ethanol in the presence of activated carbon [24].

In the BDP raw product, the main impurity, up to $15 \%$, was betulin monopropionate. Separation of betulin di- and monopropionate was carried out using column chromatography (silica gel as the solid phase and n-hexane as the mobile one). The fractions were analyzed with high-performance liquid chromatography (HPLC) using UV detection (Milichrom-A02, Econova, Russia). Three samples were prepared for investigation: A - as-received, B purified, and C - pure, with impurity content less than $15.2 \%, 3.2 \%$, and $1.4 \%$, respectively.

\subsection{Materials used for the preparation of composites.}

In our studies, four excipients were used to prepare betulin dipropionate composites. Polyvinylpyrrolidone (PVP) $\left(\mathrm{M}_{\mathrm{r}}=12,600\right)$ and polyethylene glycol (PEG) $\left(\mathrm{M}_{\mathrm{r}}=4,000\right)$ were purchased from Sigma-Aldrich, USA, and were used as-received without purification and calcination. Fumed silica $\mathrm{SiO}_{2}$ (analog of Aerosil) with a BET surface area of $\sim 400 \mathrm{~m}^{2} \mathrm{~g}^{-1}$ was 
purchased from Polysorb, Russia. Arabinogalactan $(A G)\left(M_{r}=16000\right)$ was isolated from larch (Larix sibirica) wood using the original method developed at the Institute of Chemistry and Chemical Technology SB RAS [25].

\subsection{Preparation of BDP powder composites by mechanochemical methods.}

The mechanocomposites of betulin dipropionate were prepared by milling the mixtures of BDP with the excipients in a SPEX 8000 mixer mill (CertiPrep Corp., USA) in a stainless steel vial $(60 \mathrm{~mL})$ with steel balls $(6 \mathrm{~mm}$ in diameter, total mass $30 \mathrm{~g})$. The ratio of BDP to excipients was $1: 3(\mathrm{w} / \mathrm{w})$ for calorimetric measurements and $1: 9(\mathrm{w} / \mathrm{w})$ for other experiments. Processing time varied from 5 to 30 minutes.

\subsection{Preparation of composites as the films.}

The BDP-AG composite was also prepared as a film through the following procedure. $200 \mathrm{mg}$ of BDP-AG ball-milled mixture or the mixture of initial AG (180 mg) and BDP (20 $\mathrm{mg}$ ) were dissolved in water by stirring at $37{ }^{\circ} \mathrm{C}$ for 2 days. Then, the solution was filtered using PVDF Millipore filters (Merck, Germany) with a pore diameter of $0.2 \mu \mathrm{m}$. The filtrates were evaporated at reduced pressure at 35-40 oC in IR-1M rotary evaporator (Russia). After evaporation, the samples as the thin films were obtained.

\subsection{The structural characterization of the materials.}

The crystallinity of the obtained materials was characterized using the powder X-ray diffraction (PXRD) recorded on a Bruker D8 Discover diffractometer with CuK $\alpha$ radiation at a scanning speed of $2^{\circ} \mathrm{min}^{-1}$.

Attenuated total reflectance Fourier-transform infrared (ATR-FTIR) spectroscopy was performed with a Digilab Excalibur 3100 FTIR spectrometer (Varian), a spectral resolution was better than $\pm 2 \mathrm{~cm}^{-1}$.

Scanning electron microscopy (SEM) was performed with a TM-1000 Hitachi (Hitachi Scientific Ltd, Japan) microscope.

Thermoanalytical measurements were carried out using a DSC-204 calorimeter (Netzsch). Standard aluminum crucibles were not sealed, only covered with a lid. The heating rate was $6 \mathrm{~K} \mathrm{~min}^{-1}$, gas (argon) flow was $20 \mathrm{~mL} \mathrm{~min}^{-1}$. Sample mass ranged from 5.0 to 7.8 $\mathrm{mg}$. The mass loss was measured using a TG-209 thermobalance (Netzsch) in open aluminum crucibles (diameter $8 \mathrm{~mm}$, height $4 \mathrm{~mm}$, mass $120 \mathrm{mg}$ ) at a heating rate of $6 \mathrm{~K} \mathrm{~min}^{-1}$.

The molecular weight distribution of the samples was determined by gel permeation chromatography on an Agilent 1200 chromatograph with a 1260 Infinity refractive-index detector $\left(30{ }^{\circ} \mathrm{C}\right.$, PL aquagel-OH 40, $\left.300 \times 7.5 \mathrm{~mm}, 0.1 \mathrm{M} \mathrm{LiNO}_{3}, 1 \mathrm{~mL} \mathrm{~min}{ }^{-1}\right)$. The column was calibrated using standard dextran samples (Sigma-Aldrich, USA). Chromatograms were normalized to the absorption maximum of the refractive-index detector.

\subsection{Dissolution studies.}

BDP release from the composites into the water was studied using a 705 DS dissolution tester (Varian Inc., the Netherlands). $200 \mathrm{mg}$ of the sample was placed in a vessel with $250 \mathrm{~mL}$ of water and stirred at $37 \pm 1{ }^{\circ} \mathrm{C}$. The samples taken from the solution at definite intervals were centrifuged at $800 \mathrm{rpm}$ and filtered through a Millipore membrane filter. The filtrates were evaporated and dissolved in ethanol. The concentration of BDP in the resulting ethanol solution 
was determined using a Milichrom A-02 chromatograph (Econova, Russia). The chromatographic conditions were: column temperature, $35^{\circ} \mathrm{C}$; sorbent, ProntoSIL 120-5C18 AQ 2.0*75 mm; $\mathrm{H}_{2} \mathrm{O}$ (A) - $\mathrm{CH}_{3} \mathrm{CN}$ (B), 80-100-100\% B, $100 \mu \mathrm{L} \mathrm{min}{ }^{-1}$. The detection wavelengths were 200,210 , and $220 \mathrm{~nm}$. The standards were EtOH solutions. The results were recalculated for the initial filtrate volume.

\subsection{Anticancer activity assay.}

The anticancer activity of BDP-AG composites was assessed by their ability to induce apoptosis and necrosis in Ehrlich's ascites adenocarcinoma (EAC) cells and by the data of ionic homeostasis according to the method described in [26].

Human lung adenocarcinoma A549 cells and normal lung epithelial MRC5 cells (American Tissue Culture Collection, USA) were also used to assay anticancer activity in accordance with the methodology given in [27, 28].

Statistical processing of the results was performed using the Biostat and Stagraphics Plus programs. In addition, the reliability of differences between readings $(p<0.05)$ was evaluated using the Mann - Whitney criterion.

\section{Results and Discussion}

\subsection{Isolation and purification of betulin dipropionate.}

3.1.1. Isolation of betulin dipropionate from birch bark.

To isolate betulin dipropionate from birch bark, the one-step extraction method was developed [24, 29]. This method is based on combining the stage of betulin extraction from birch bark and its acylation with propionic acid. It differs from other methods of producing betulin esters based mainly on betulin acylation reactions and requiring an obligatory additional stage of betulin isolation from birch bark $[19,30]$.

\subsubsection{Identification and purification of betulin dipropionate.}

After recrystallization from ethyl alcohol, betulin dipropionate is a white powder with a purity of $85 \%$ and a melting point of $149{ }^{\circ} \mathrm{C}$. Noteworthy, the crude product contains betulin monopropionate, betulin, and lupeol, along with betulin dipropionate, as confirmed by gas chromatography/mass spectrometry [24].

As a result of purification, the final product's impurities were less than $1.4 \%$. As a result, rather pure betulin dipropionate was obtained with the structure: orthorhombic P212121, a = 127.409(2), $\mathrm{b}=157.316(3), \mathrm{c}=159.810(3) \mathrm{nm}$ [31]. The melting point of this sample (163.6 ${ }^{\circ} \mathrm{C}, \Delta_{\mathrm{f}} \mathrm{H}=33 \mathrm{~kJ} \mathrm{~mol}^{-1}$ ) was found to exceed the values reported for a less pure sample (Figure 3 ). The sample of molten betulin dipropionate does not crystallize on cooling and remains in a glassy state under ambient conditions, showing glass transition near $65{ }^{\circ} \mathrm{C}$ under reheating (Figure 3).

\subsubsection{The effect of ball-milling on the physicochemical properties of betulin dipropionate.}

The structure of ball-milled BDP was checked in order to clarify its polymorphic form. Figure 4 shows the PXRD patterns of betulin dipropionate before and after its ball-milling. 
After 15 min of milling, the reflections are significantly broadened and demonstrate lower intensities owing to the disordering of the crystalline structure.

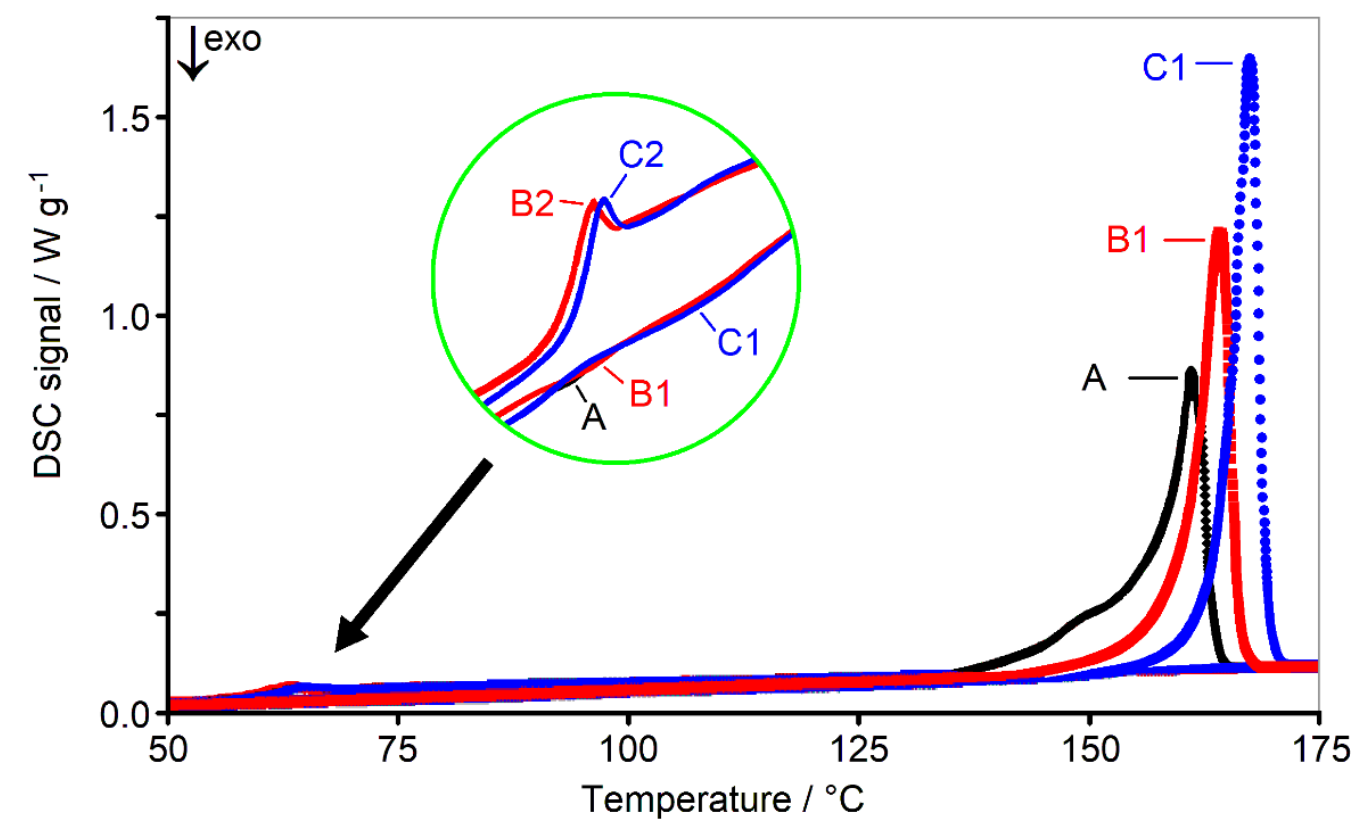

Figure 3. DSC curves of betulin dipropionate of different purity: A - as received, B - purified, C - highest purity. Numbers 1 and 2 indicate the $1^{\text {st }}$ and the $2^{\text {nd }}$ heating, respectively. The inset shows the difference in heat capacity between the $1^{\text {st }}$ and $2^{\text {nd }}$ runs and glass transition near $65^{\circ} \mathrm{C}$.

However, the positions of the main reflections of the BDP sample remain practically unchanged, which indicates the absence of phase transitions under processing conditions. Ball milling for $30 \mathrm{~min}$ leads to an even greater decrease in the intensity of reflections, which indicates a partial amorphization of the sample. HPLC analysis shows that the chemical composition of betulin dipropionate samples does not change after mechanical activation. Thus, the result of ball milling is a disordering of the crystal structure of betulin dipropionate. According to this, the melting point of ball-milled BDP $\left(154.7^{\circ} \mathrm{C}\right)$ and enthalpy of its fusion $\left(42 \mathrm{~J} \mathrm{~g}^{-1}\right.$ ) are lower compared to the starting sample (Figure 5) [31]. A thermal effect near 75 ${ }^{\circ} \mathrm{C}$ was observed on the DSC curve, which may be connected with a phase transition in the ball-milled BDP as it was observed for betulin [32] and betulin diacetate [33]. The exact nature of the BDP phase transitions, as well as their mechanisms, requires further detailed study.

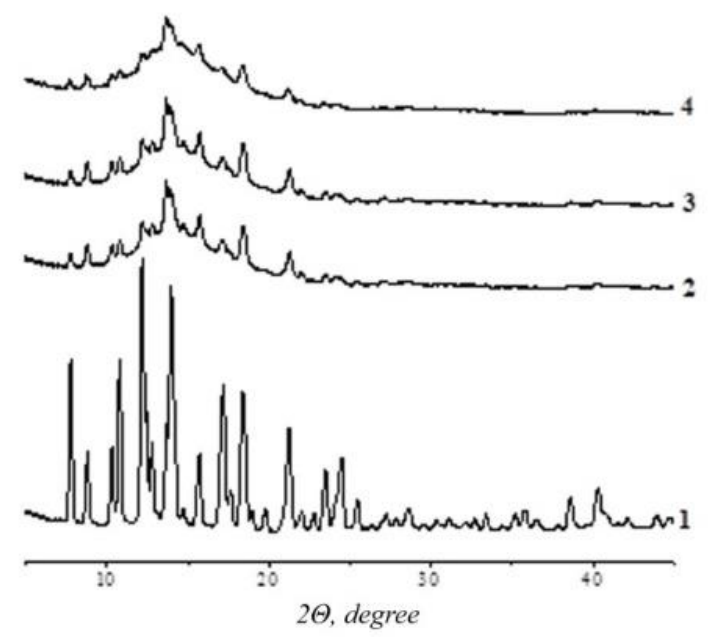

Figure 4. PXRD patterns of initial betulin dipropionate (1) and the sample after its ball-milling for 5 (2), 15 (3), and 30 minutes (4). 


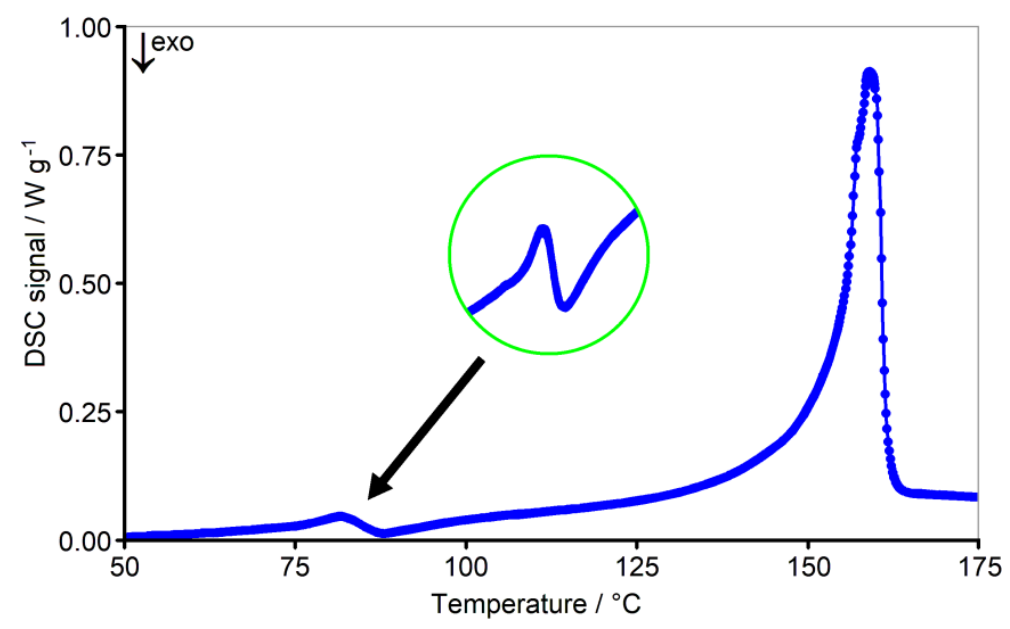

Figure 5. DSC curve of the ball-milled BDP.

\subsection{Composites of betulin dipropionate with synthetic polymers.}

3.2.1. Composites of betulin dipropionate with polyvinylpyrrolidone.

Polyvinylpyrrolidone (PVP) is one of the most popular excipients for obtaining solid dispersions of the drugs [34,35]. We reported the preparation of betulin-PVP mechanocomposite, which showed an increased solubility of betulin [33]. It was shown in the in vivo tests that at equal doses of preparations, the betulin - PVP mechanocomposite exhibited higher gastroprotective activity in comparison with initial betulin [33]. In vitro tests showed that this composite exhibited higher antitumor activity in comparison with the initial substance [36,37].

PVP $\left(M_{r}=12600\right)$ was used to prepare BDP composites using mechanochemical methods. Figure 6 shows a DSC curve of a ground mixture of BDP - PVP (1:9, w/w) [31]. A large endothermic peak of PVP dehydration starts near room temperature and ends near 100 ${ }^{\circ} \mathrm{C}$, with the maximum at about $75{ }^{\circ} \mathrm{C}$. TG analysis shows that the second step of mass loss starts immediately after the first one. The wavy DSC curve between 100 and $175^{\circ} \mathrm{C}$ probably indicates an endothermic second step of PVP dehydration and exothermic dissolution of betulin dipropionate in the polymer (Figure 6) [31]. The bulk crystalline phase of betulin dipropionate in the ground mixture with PVP is not detected.

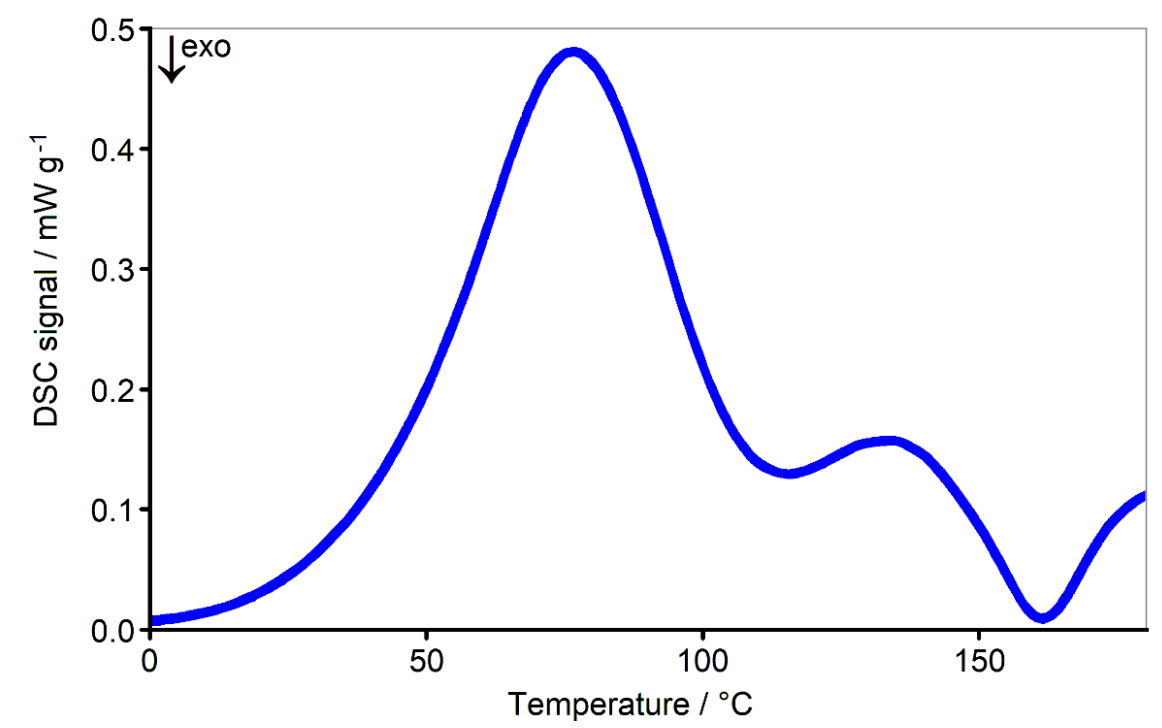

Figure 6. DSC curve of the ball-milled mixture of betulin dipropionate with PVP. 
3.2.2. Composites of betulin dipropionate with polyethylene glycol.

Polyethylene glycol (PEG) is often used to prepare the composites of poorly watersoluble drugs with the purpose of their solubilization and providing a long and safe circulation of drugs [39,40]. In our studies, PEG was used previously to prepare solid dispersions with betulin and betulin diacetate by ball-milling [33,41]. In the case of betulin - PEG mixtures, there was almost complete amorphization of betulin under ball-milling. At the same time, in the powder X-ray diffraction patterns of BDA - PEG ball-milled mixtures, no significant changes in the intensities of reflections were observed. As proven by DSC and model hot stage optical microscopy experiments, ball milling of these mixtures leads to the formation of a PEG melt, dissolution of BDA in the melt, and crystallization of BDA from the melt [41]. It was shown with the model of acute renal failure in rats that the ball-milled composite of betulin with PEG increased the actual survival of animals under the conditions of acute renal failure [42].

The DSC curve of the 1:9 BDP - PEG $\left(\mathrm{M}_{\mathrm{r}}=4000\right)$ ball-milled mixture is shown in Figure 7 [31]. An intense endothermic peak near $65^{\circ} \mathrm{C}$ indicates PEG melting. No traces of betulin dipropionate melting are observed up to $160{ }^{\circ} \mathrm{C}$. Instead, the DSC signal deflects downward starting from $140{ }^{\circ} \mathrm{C}$, indicating evidently exothermic processes in the sample, most likely dissolution of betulin dipropionate in PEG. TG analysis did not reveal any mass loss in this temperature range.

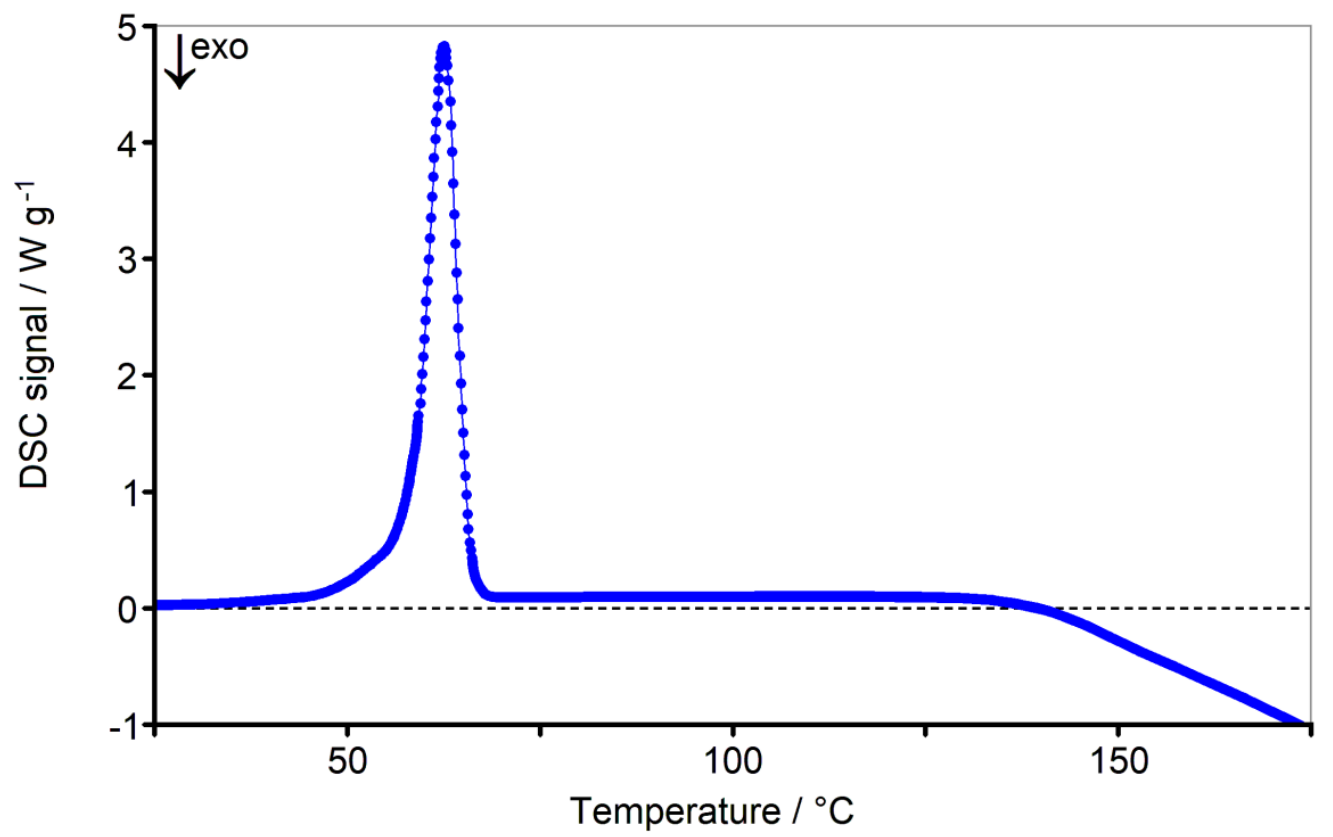

Figure 7. DSC curve of the ball-milled mixture of betulin dipropionate with PEG.

It can be concluded that betulin dipropionate interacts well with PEG and PVP, so its melting peak disappears almost completely after ball-milling with the excipients. The obtained composites may turn out to be promising materials for use in pharmacy.

\subsection{Composites of betulin dipropionate with arabinogalactan.}

Water-soluble polysaccharide arabinogalactan is widely used nowadays due to its antioxidant, immunomodulatory activity, and component for drug delivery systems [43-46].

In our studies, the composites of BDP with $\mathrm{AG}$ were obtained in powder form and as a thin water-soluble film. 


\subsubsection{Powder BDP-AG composite.}

Scanning electron microscopy (SEM) was used to assess the particle morphology and the possibility of interaction between the components in the 1:9 BDP - AG ball-milled mixture. The SEM images of the pure BDP indicate the presence of crystalline particles of regular size and block shape (Figure 8a). The SEM images of ball-milled mixtures (Figure 8b) show a characteristic morphology as the small-sized particles are prone to aggregation, probably interacting at the contacts with each other [27,28]. The same morphology was observed for betulin diacetate alone and ball-milled BDA-AG mixture (Figure $8 \mathrm{c}, \mathrm{d}$ ).

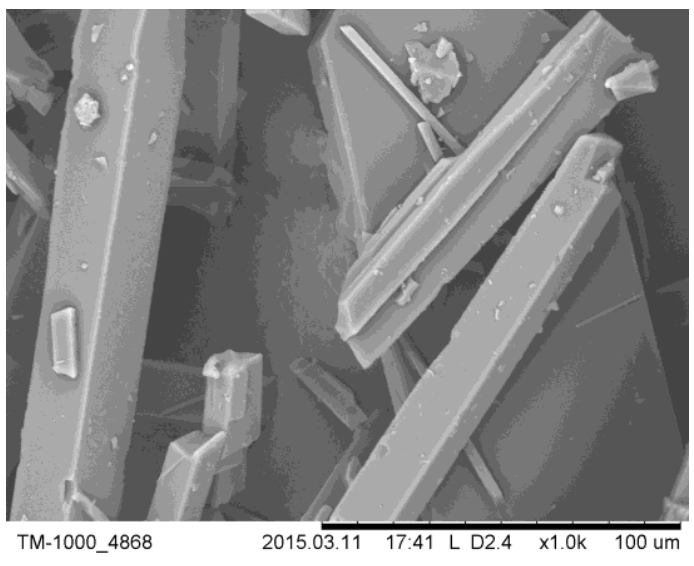

a

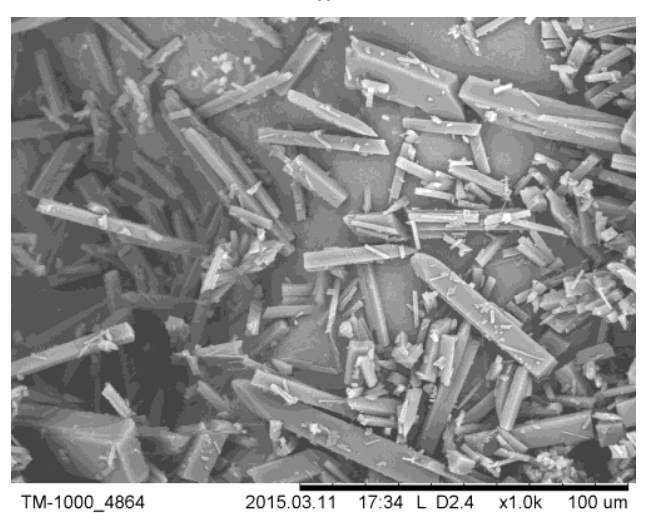

$\mathrm{c}$

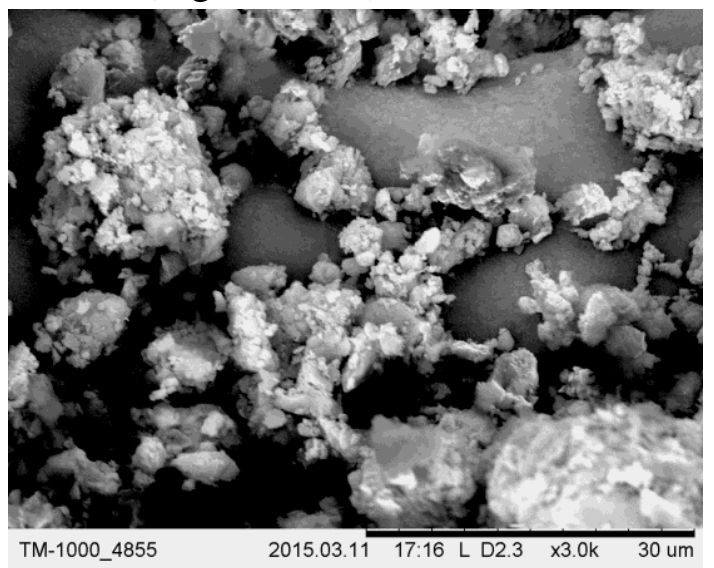

b

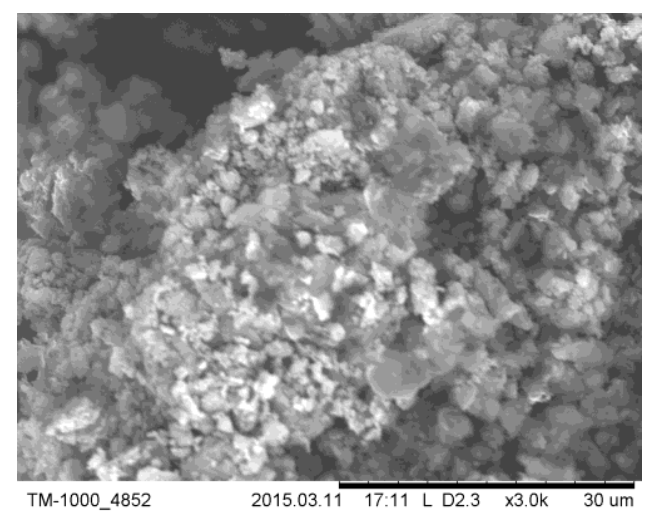

d

Figure 8. Scanning electron microscopy images of (a) BDP; (b) ball-milled BDP-AG mixture; (c) BDA; (d) ball-milled BDA-AG mixture.

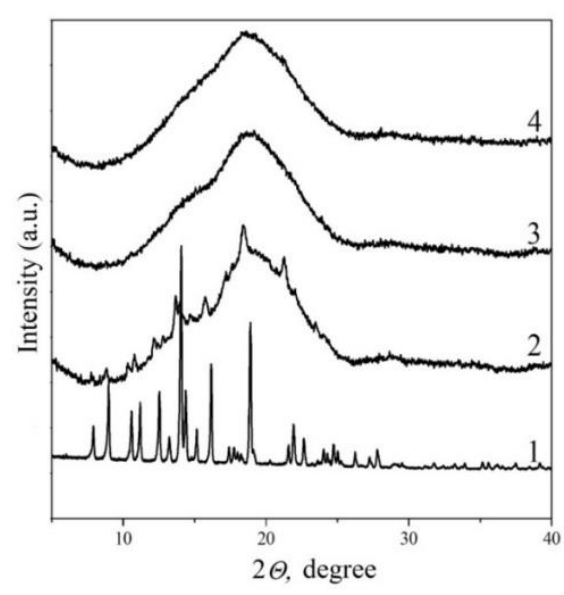

a

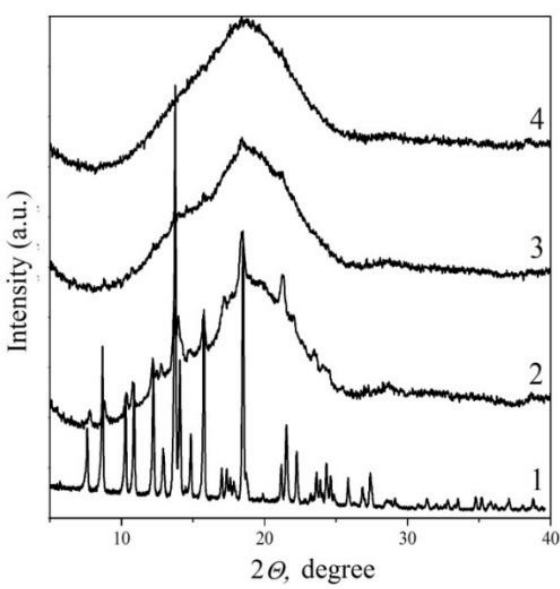

b

Figure 9. (a) PXRD patterns of the initial BDP (1) and the mixtures of BDP with AG after ball-milling for 5 (2), 15 (3), 30 (4) min; (b) the same for BDA. 
The PXRD patterns of the BDP - AG milled mixtures (Figure 9a) show that the betulin ester phase is amorphous after milling, thus suggesting the distribution of BDP in the polymer with the formation of a composite material. The comparison with BDA sample (Figure 9b) shows that BDP became amorphous faster than BDA, which may be due to their different mechanical properties.

In the ATR-FTIR spectra of the BDP-AG ball-milled mixture, the profile of $\mathrm{C}=\mathrm{O}$ stretching vibration in the BDP molecule changed compared to the ball-milled BDP sample (Figure 10a). This suggests that hydrogen bonds are formed at least for the part of the molecules of BDP in the ball-milled mixtures. The change of $\mathrm{C}=\mathrm{O}$ stretching vibration profile was also observed for BDA-AG ball-milled mixture (Figure $10 \mathrm{~b}$ ).
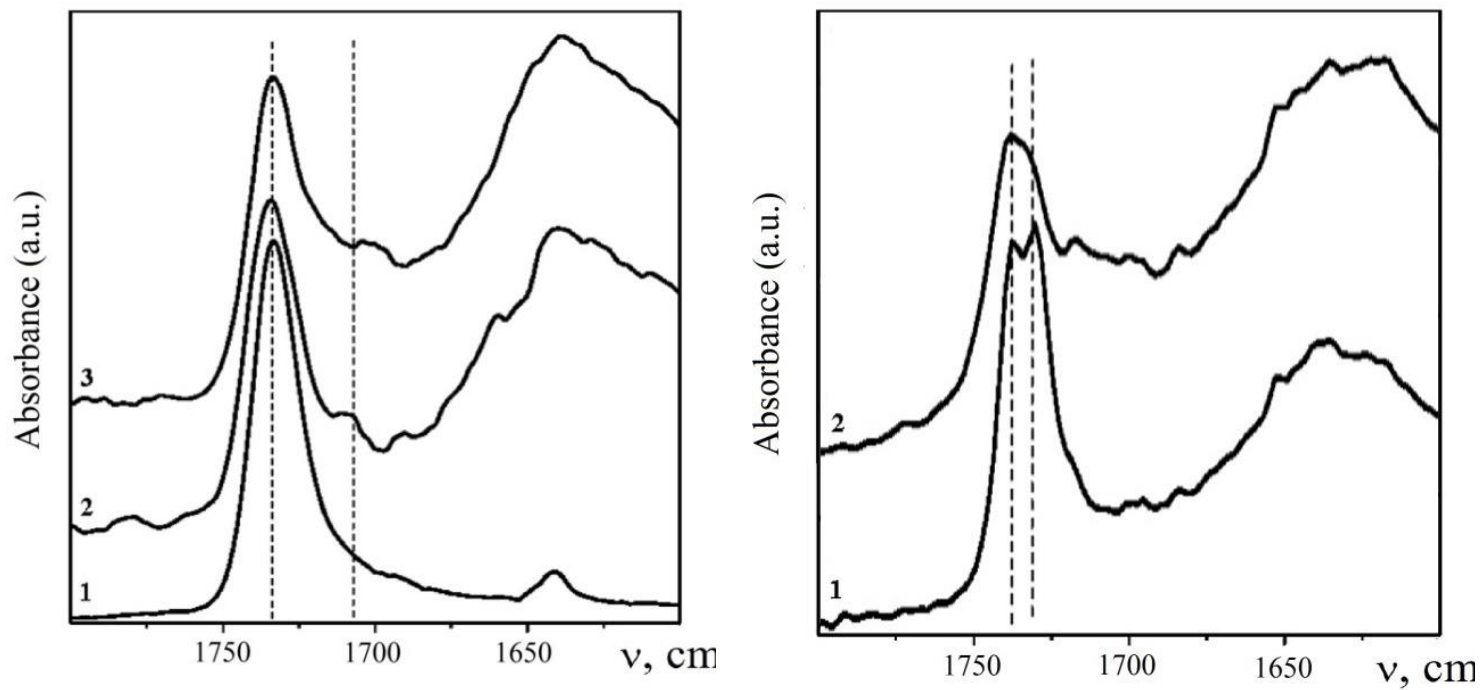

a

b

Figure 10. ATR-FTIR spectra of (a) BDP ball-milled for 30 min (1), 1:9 BDP-AG mixture ball-milled for 15 (2) and $30 \mathrm{~min}$ (3); (b) 1:9 BDA-AG mixture, initial (1) and ball-milled for 15 min (2).

The DSC curve of the BDP - AG ball-milled mixture is shown in Fig. 11. A large endothermic peak of dehydration starts near room temperature and ends near $150{ }^{\circ} \mathrm{C}$. The peak of pure betulin dipropionate melting (or, more precisely, its trace) is seen in the insert with the maximum at $160^{\circ} \mathrm{C}$. The presence of this peak indicates that, possibly, not the whole substance has passed into the amorphous state, or some part of the substance was crystallized upon heating.

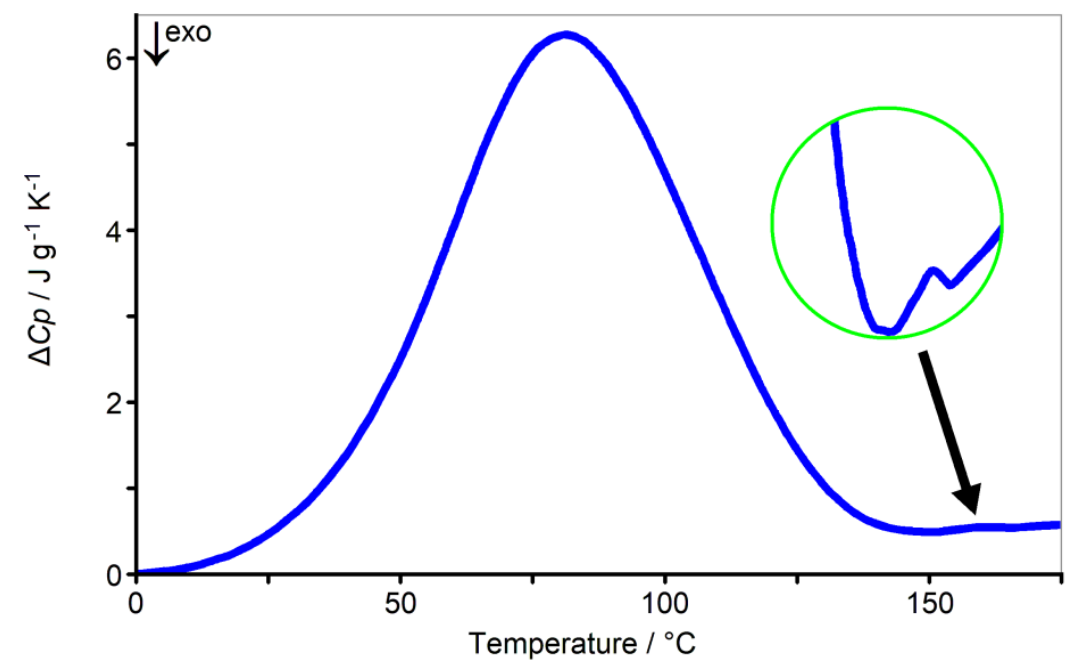

Figure 11. DSC curve of the ball-milled mixture of betulin dipropionate with AG. 
Nevertheless, the absence of a true BDP melting peak on the DSC curve indicates the formation of a rather strong BDP - AG composite upon ball-milling. This can be the distribution of molecules (or ensembles of molecules) of BDP in the polymer or the dispersion of BDP to a nanosized state with the formation of a homogeneous mechanical mixture with AG. The stability of such composite upon heating may be due to the interaction of the components during mechanical activation.

Upon dissolution of the BDP-AG ball-milled mixture in water, the concentration of BDP increased up to 4 times in comparison with the initial substance [27]. The dynamics of dissolution of BDP from physical and ball-milled mixtures with AG are shown in Figure 12a. In the case of a ball-milled mixture, the rate of dissolution and the concentration of BDP in solution were higher than the physical mixture. The same is observed for betulin diacetate (Figure 12b). However, it should be noted that despite the fact that the solubility of BDA is 1.5 times higher than the solubility of BDP (see curves number 1), in the case of the dissolution of BDP-AG ball-milled mixture, the concentration of BDP in the solution even slightly exceeds that of BDA. This may be due to the structure of molecular complexes formed during ballmilling.
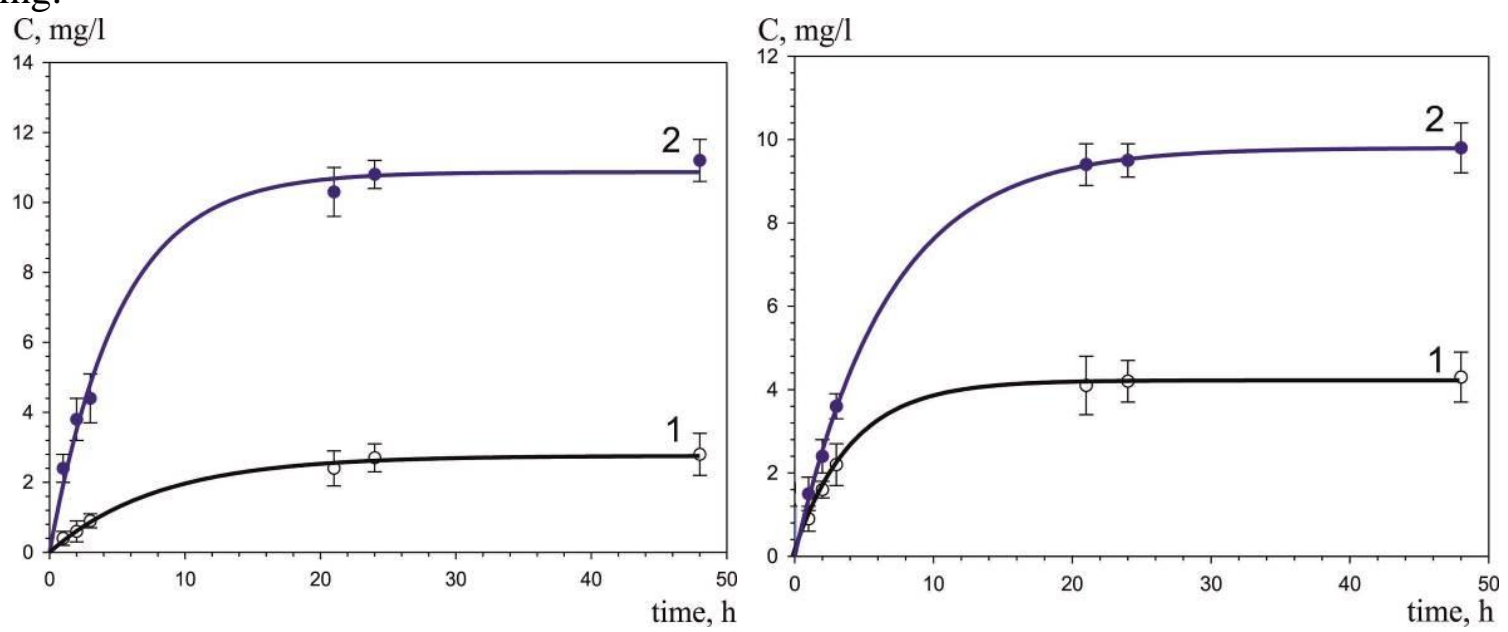

a

$\mathrm{b}$

Figure 12. Dissolution curves of (a) 1:9 BDP - AG physical (1) and ball-milled (2) mixtures; (b) 1:9 BDA - AG physical (1) and ball-milled (2) mixtures.

\subsubsection{Thin films of betulin dipropionate composites.}

The samples obtained by evaporating the aqueous solutions of AG and its mixtures with BDP were slightly colored (yellowish) amorphous films $\sim 10 \mu \mathrm{m}$ thick. These films were transparent and flexible. The films were quickly and completely soluble in a much smaller quantity of water than was used for their preparation. According to HPLC data, the content of betulin dipropionate in the film was about $2 \%(\mathrm{w} / \mathrm{w})$. The dissolution of the film in water gives a solution with BDP concentration of $0.15-0.18 \mathrm{mg} / \mathrm{mL}$.

Dushkin et al. [47] showed that ball-milling of AG resulted in a decrease in the molecular weight of the polymer. The same effect was also observed for the ball-milled mixtures of AG with BDA [48]. After the ball-milled AG was dissolved in water and then the solvent was evaporated, the molecular weight was partially restored. Moreover, the gelpermeation chromatogram of the BDA-AG ball-milled mixture after dissolution in water and subsequent solvent evaporation acquired the shape of that for the starting AG, suggesting crosslinking of the polymer chains due to the formation of intermolecular complexes in solution. 
The gel chromatogram of BDP - AG film, obtained by dissolving the ball-milled mixture in water, has two main maxima with $\lg \mathrm{M}=4.2$ and 3.8 in accordance with arabinogalactan initial molecular mass and the mass after ball-milling, respectively (Figure 13). Upon dissolution of BDP-AG film in water, the maximum intensity with $\lg \mathrm{M}=3.8$ goes down. This may be due to the complexation of BDP with several AG macromolecules in solution with the formation of mobile intermolecular complexes of BDP with AG [47].

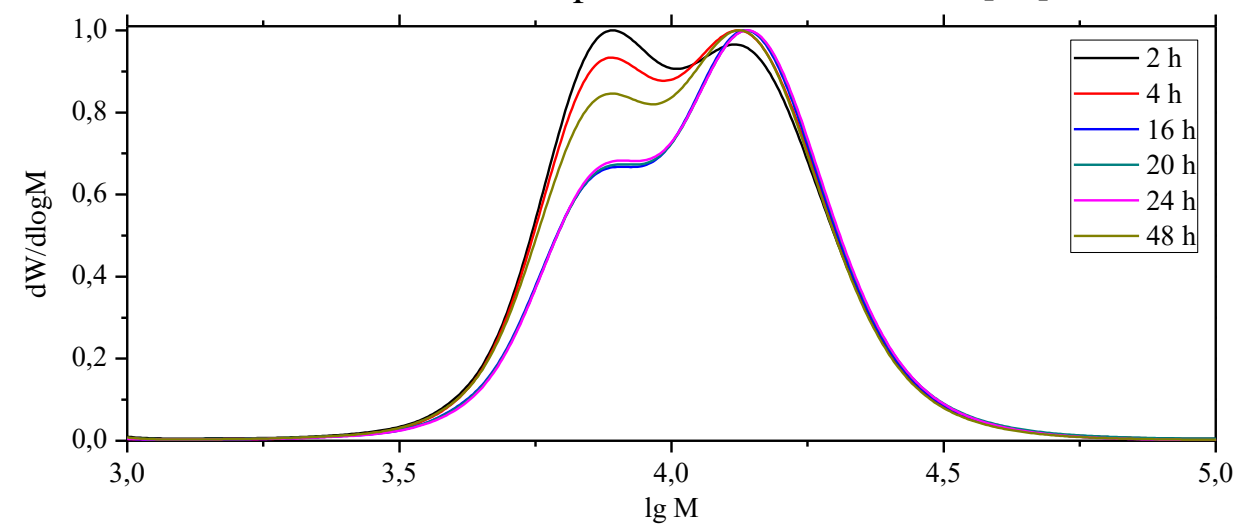

Figure 13. Gel-permeation chromatograms of solutions of the BDP - AG film in water taken at different dissolution time $\left(\mathrm{T}=37^{\circ} \mathrm{C}\right)$.

\subsection{Composites of betulin dipropionate with fumed silica.}

Silica is known as a generally safe, non-toxic, and biocompatible material. The welldefined and tunable chemistry of silica nanoparticles allows a precise design of nanosized probes and carriers [49]. The polymeric structure of silica nanoparticles consists of siloxane ($\mathrm{Si}-\mathrm{O}-\mathrm{Si}-\mathrm{O}-)$ structures with highly concentrated silanol ( $\mathrm{Si}-\mathrm{OH})$ groups on their surface that provide intrinsic hydrophilicity and favorable colloidal stability.

Fumed silica was used to prepare the composite with BDP by ball-milling. In contrast to the previous cases, the $\mathrm{SiO}_{2}$ carrier is not soluble in water, and the dissolution mechanism could be different from that of the composites with water-soluble polymers.

The ball-milling of a mixture of BDP with silica leads to homogenization of the mixture as a result of dispersion of the components and the formation of mechanically activated composites [50]. The original BDP is composed of crystals ranging from 10 to $100 \mu \mathrm{m}$ (Figure 14 a).

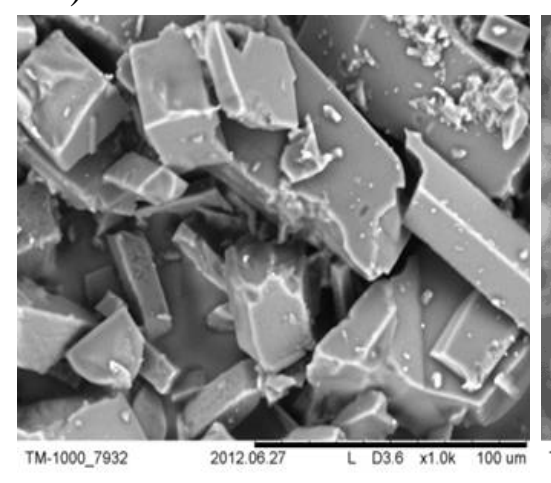

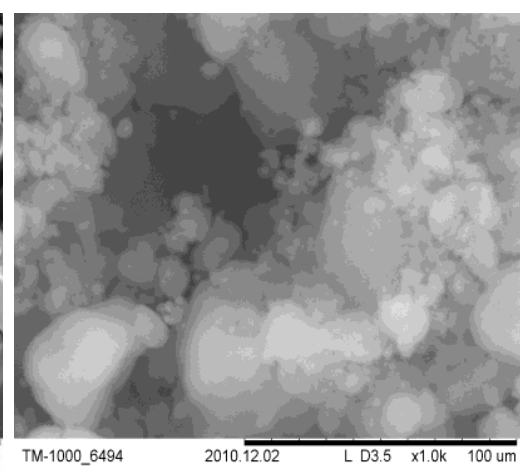

$\mathrm{b}$

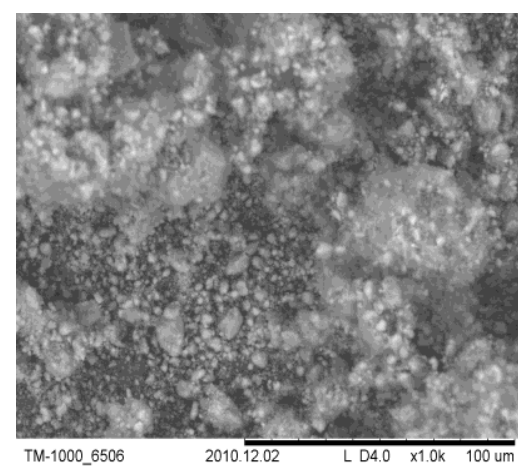

c

Figure 14. Scanning electron microscopy images of BDP crystallized from (a) ethanol; (b) fumed silica; (c) the $\mathrm{BDP}-\mathrm{SiO}_{2}$ mixture ball-milled for 15 minutes.

The sizes of silica particles are $5-40 \mathrm{~nm}$ (Figure $14 \mathrm{~b}$ ). As a result of ball-milling, betulin dipropionate crystals are crushed to a size of 5-10 $\mu \mathrm{m}$. The ball-milled mixture of BDP 
with $\mathrm{SiO}_{2}$ is homogeneous and consists of particle aggregates with a size of 5-30 $\mu \mathrm{m}$ (Figure $14 \mathrm{c}$ ). HPLC analysis confirmed that the chemical composition of betulin dipropionate samples did not change after ball-milling with silica.

Figure 15 shows that after ball-milling for 5 minutes, there were reflections at the PXRD pattern of $\mathrm{BDP}-\mathrm{SiO}_{2}$ mixture, indicating the presence of crystalline BDP. The reduction in the intensity of reflections and their broadening with an increase in the duration of ballmilling from 5 to $30 \mathrm{~min}$ was observed. After ball-milling for $15 \mathrm{~min}$ (Figure 15, curve 2), almost complete disappearance of BDP reflections was observed, which indicated its amorphization.

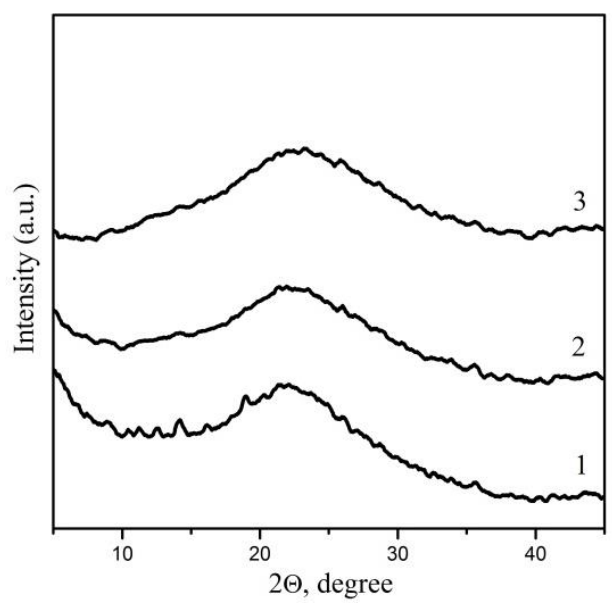

Figure 15. PXRD patterns of $\mathrm{BDP}-\mathrm{SiO}_{2}$ mixture ball-milled for 5 (1), 15 (2), and 30 minutes (3).

A DSC curve of the ball-milled mixture of betulin dipropionate with $\mathrm{SiO}_{2}$ is shown in Figure 16. An endothermic peak of $\mathrm{SiO}_{2}$ dehydration starts near room temperature and ends above $175{ }^{\circ} \mathrm{C}$, with the maximum near $75{ }^{\circ} \mathrm{C}$. No trace of betulin dipropionate melting is detected. It can be concluded that mechanical treatment leads to the formation of betulin dipropionate - silica composite material containing BDP in the amorphous state.

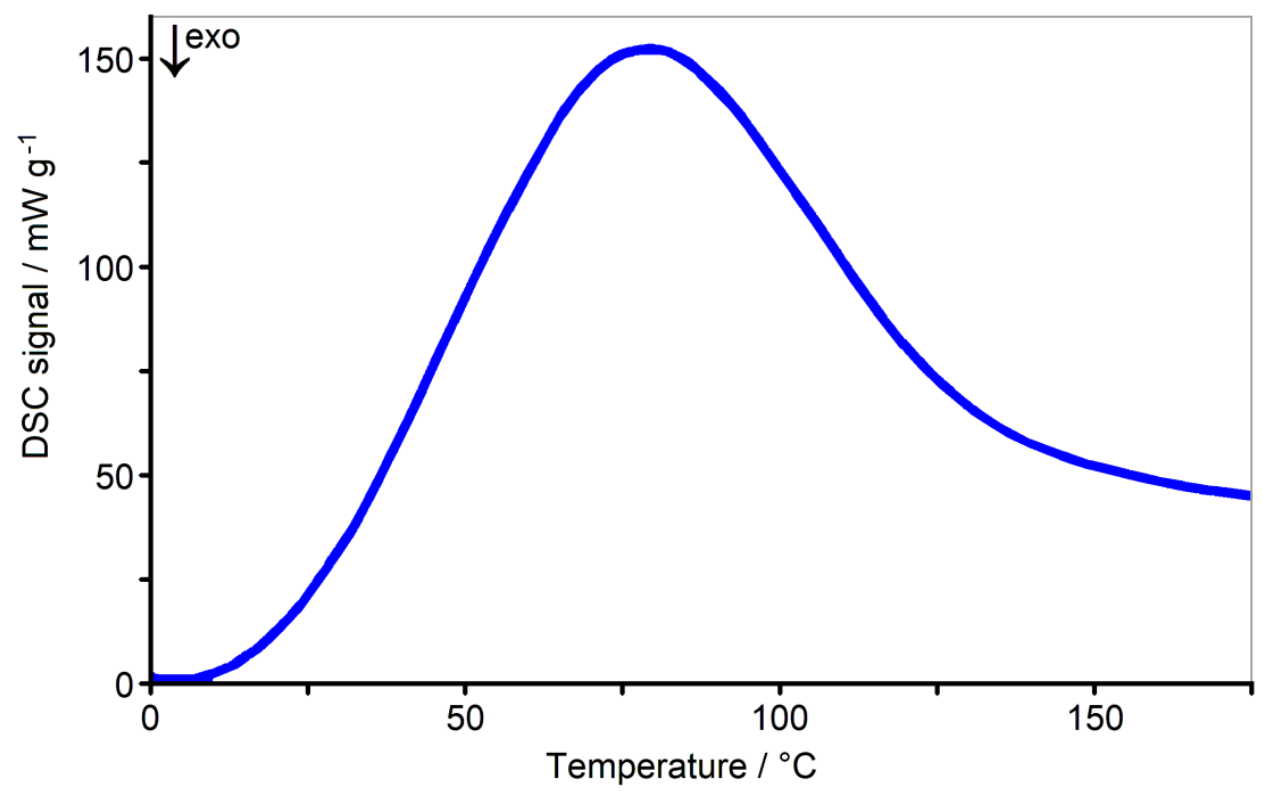

Figure 16. DSC curve of the ball-milled mixture of betulin dipropionate with $\mathrm{SiO}_{2}$.

Figure 17 shows that upon dissolution of a physical mixture of $\mathrm{BDP}$ with $\mathrm{SiO}_{2}$, the concentration of BDP in water was $0.7 \mathrm{mg} / \mathrm{L}$ at a dissolution time of 24 hours. The solubility of $\mathrm{BDP}$ in water increases after ball-milling of $\mathrm{BDP}$ with $\mathrm{SiO}_{2}$ for 15 minutes and after 24 hours reaches $6.1 \mathrm{mg} / \mathrm{L}$, which is approximately 8 times higher than the solubility of the 
physical mixture of the starting substances. With an increase in the duration of mechanical activation of the mixtures of BDP with silica to $30 \mathrm{~min}$, the concentration of BDP in the solution does not increase, possibly due to the enlargement of aggregates of betulin dipropionate with silica, which can prevent the transition of BDP into solution.

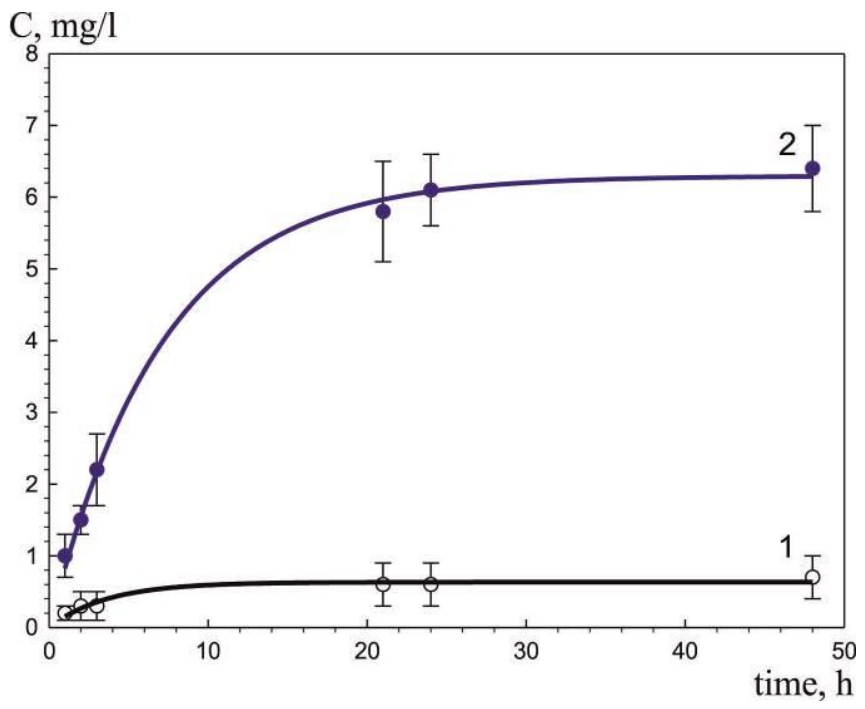

Figure 17. Dissolution curves of BDP - $\mathrm{SiO}_{2}$ physical (1) and ball-milled (2) mixtures.

The increased water solubility of betulin dipropionate contained in the $\mathrm{BDP}-\mathrm{SiO}_{2}$ composite can be associated with BDP amorphization during mechanical activation in the presence of silica [50].

\subsection{Anticancer activity of betulin dipropionate and its composites.}

Over the recent years, several studies have been concerned with elucidating the molecular mechanisms of the anticancer effect of betulin and its derivatives [7-13, 51-58]. Currently, three main mechanisms of the cytotoxic effect of betulin-containing substances on cancer cells are elucidated: (1) anti-proliferative activity by inhibiting topoisomerase I and II; (2) apoptosis activation; (3) anti-angiogenic activity within the tumor.

Among betulin derivatives, betulinic acid is the most studied substance as far as the mechanism of anticancer action is concerned. In isolated mitochondria, betulinic acid induces the loss of transmembrane potential, enhancing the release of cytochrome $\mathrm{c}$ and apoptosisinducing factor, which is sufficient for caspases cleavage and nuclear fragmentation [52, 53]. In human melanoma, betulinic acid causes the loss of apoptosis protease activator protein1 (APAF-1) expression, which prevents caspase-9 activation promoting resistance to programmed cell death. Betulin derivatives activate caspase- 3 and fragmentation of genomic DNA [55]. It activates nuclear factor-kappaB, a key regulator of stress-induced transcription activation, promoting apoptosis in a cell type-specific manner [56]. Remarkably, betulinic acid demonstrates selective cytotoxicity on cancer lymphocytes but not on normal ones [57]. It induces apoptosis in normal keratinocytes as well as in cancer, but to less extent than in normal ones; moreover, it is capable of inducing differentiation of normal cells into corneocytes without provoking apoptosis [51, 57]. Although betulin is a well-known antioxidant [58] blocking reactive oxygen species (ROS) accumulation in normal cells $[59,60]$, in cancer cells, it promotes ROS production [61].

Figure 18 schematically summarizes the main mechanisms of the anticancer effect of betulinic acid. These mechanisms may play a role in the case of other betulin derivatives as well. 
Betulin and its derivatives were tested for their cytotoxic effect on different cell lines, including hematological malignancies, melanoma, neuroblastoma, medulloblastoma, Ewing sarcoma, myeloma, glioblastoma, head and neck, breast, colon, gastric, cervix, hepatocellular, lung, pancreatic, renal, ovarian, and prostate cancers [7-13, 56, 57, 60-62]. Therefore, they seem to be promising anticancer drugs. Only poor water solubility of betulin derivatives is a bottleneck for their use in the clinic. In the current paper, we focus on betulin dipropionate because its composites demonstrate enhanced solubility.

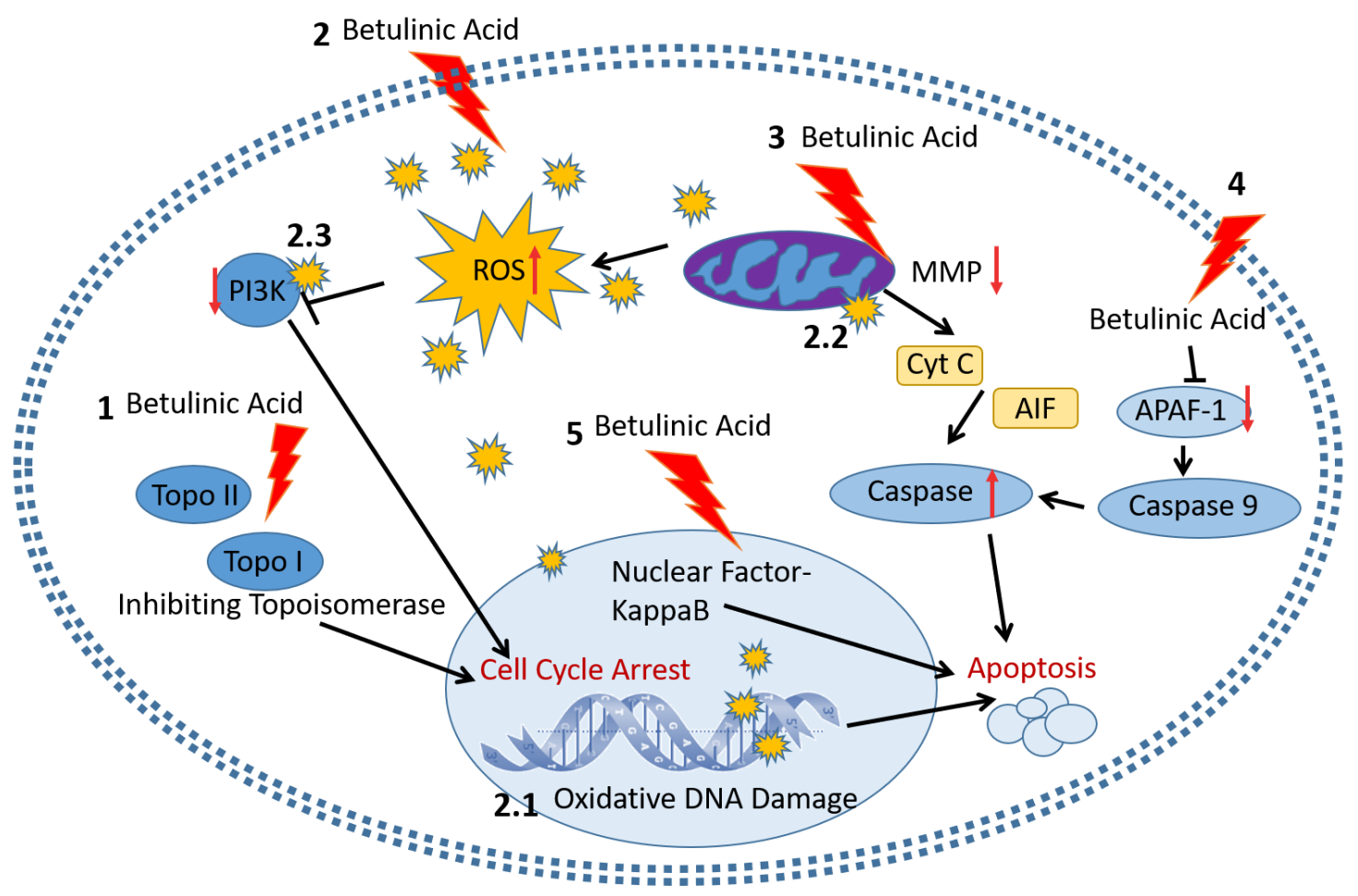

Figure 18. Schematic representation of the mechanisms of betulinic acid and betulin-containing compounds cytotoxicity on cancer cell. Betulinic acid-induced cell cycle arrest by inhibiting topoisomerase I and II (Topo I, Topo II) (1). Betulinic acid-induced an increase in the content of intracellular ROS (2), which causes oxidative DNA damage (2.1); mitochondrial membrane permeabilization (2.2) followed by caspase passway activation and apoptosis; inhibition of phosphoinositide 3-kinases (PI3K) causing cycle arrest (2.3). Betulinic acidmediated apoptosis mitochondrial (increase in mitochondrial membrane permeabilization (MMP) provokes cytochrome C (Cyt C) and apoptosis-inducing factor (AIF) release, which is sufficient for caspases cleavage and nuclear fragmentation) (3). Betulinic acid inhibited apoptosis protease activator protein-1 (APAF-1) expression, which prevents caspase-9 activation promoting resistance to programmed cell death (4). Betulinic acid-activated nuclear factor-kappa B, promoting apoptosis in a cell-type-specific manner (5).

\subsubsection{Toxicological study.}

The toxicological study at the accredited testing center in Krasnoyarsk (Russia) showed that betulin dipropionate and its composite with $\mathrm{AG}$ at a dose of $4000 \mathrm{mg} / \mathrm{kg}$ were non-toxic and, according to the international toxicological classification, these substances could be assigned to class 4: low-toxic substances [24]. This gives rise to interest in studying the pharmacological activity of these substances.

3.5.2. In vitro study of anticancer activity of betulin dipropionate - AG composite against Ehrlich ascites carcinoma cells.

Betulin dipropionate and its composites demonstrated anticancer activity in Ehrlich ascites carcinoma (EAC) cells inducing apoptosis [63]. The ball-milled BDP-AG mixture 
suppressed the growth of cancer cells in culture more effectively than BDP or AG alone, inducing apoptosis (Figure 19).

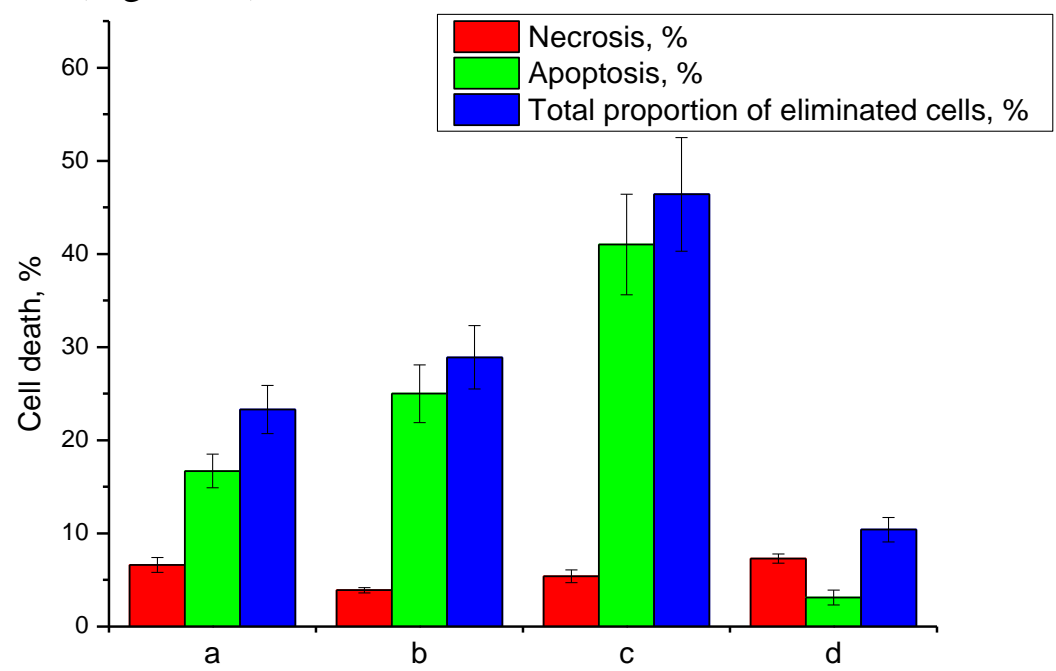

Figure 19. Effect of AG (a), BDP (b) and BDP-AG composite (c) on the Ehrlich ascites adenocarcinoma cells elimination in comparison with control $(\mathbf{d})(n=5, p<0,05)$.

It has been shown that BDP-AG composite and the initial substances BDP and AG change the ionic homeostasis of the cell, reducing the concentration of intracellular potassium and sodium, and to a greater extent, the content of potassium cations in the cell decreased under the influence of the BDP - AG ball-milled composite [63]. A simultaneous decrease in the content of potassium and sodium in a cell indicates the initiation of apoptosis. It can be concluded that the BDP-AG composite activated the apoptosis of EAC cells to a greater extent than the starting BDP and AG.

The data on the assessment of apoptosis and necrosis in EAC cells under the influence of the studied substances in combination with the studies of ionic hemostasis in the cells indicate that the antitumor effect of BDP-AG ball-milled mixture is greater than that of the initial arabinogalactan and betulin dipropionate [63].

3.5.3. In vitro study of anticancer activity of betulin dipropionate - AG composite against human lung adenocarcinoma cells.

It was shown that pure BDP and its physical and ball-milled mixtures and the films, in contrast to AG, in varying degrees caused translocation of phosphatidylserine in the cells of lung adenocarcinoma A549, indicating apoptosis initiation (Figure 20) [27,28]. Cytotoxicity of pure BDP was significantly higher than that of pure BDA (Figure 21). BDP-AG and BDAAG films induced apoptosis in $86 \%$ and $82 \%$ of cells in culture, respectively. The activities of the physical mixtures of BDA and BDP with AG were lower than those of pure substances but higher than those of the ball-milled mixtures.

Due to the fact that the ratio of the substances in the BDP (or BDA) - AG physical or ball-milled mixtures were equal to 1:9 (w/w), the activity of such samples would decrease by a factor of 10 compared to pure BDP (or BDA). However, the activity was 6-10 times higher in the case of BDA and 2-4 times higher for BDP. The effect was even more pronounced for film composites, although the content of the active substance in them was 4-5 times less than in the physical mixtures or ball-milled composites. Obviously, the structure of molecular complexes formed under ball-milling will differ from those obtained by dissolution of physical mixtures due to the rupture of polymer chain under ball-milling. On the other hand, in the case 
of the films, the complexes were prepared, which can differ from those prepared in the case of physical or ball-milled mixtures. Thus, the structure of the complexes and their properties might play essential roles in the biological activity of the BDP - AG composites.

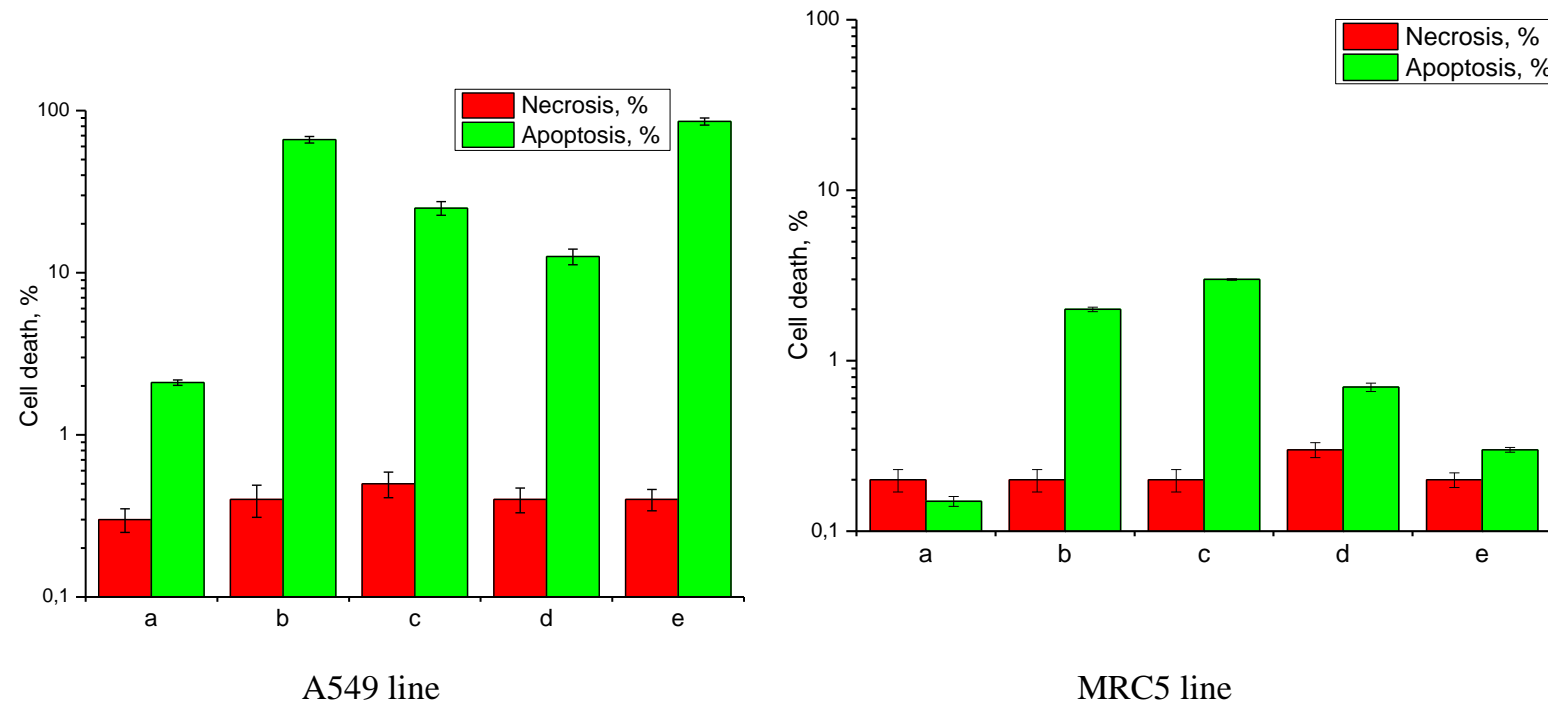

Figure 20. Effect of BDP and its composites with AG on the viability of healthy MRC5 and cancer A549 lung cells: a) control (intact cells); b) BDP; c) BDP - AG (1:9, w/w) initial mixture; d) BDP - AG (1:9, w/w) mechanocomposite; e) BDP - AG composite as a film ( $\mathrm{n}=5, \mathrm{p}<0,05)$.
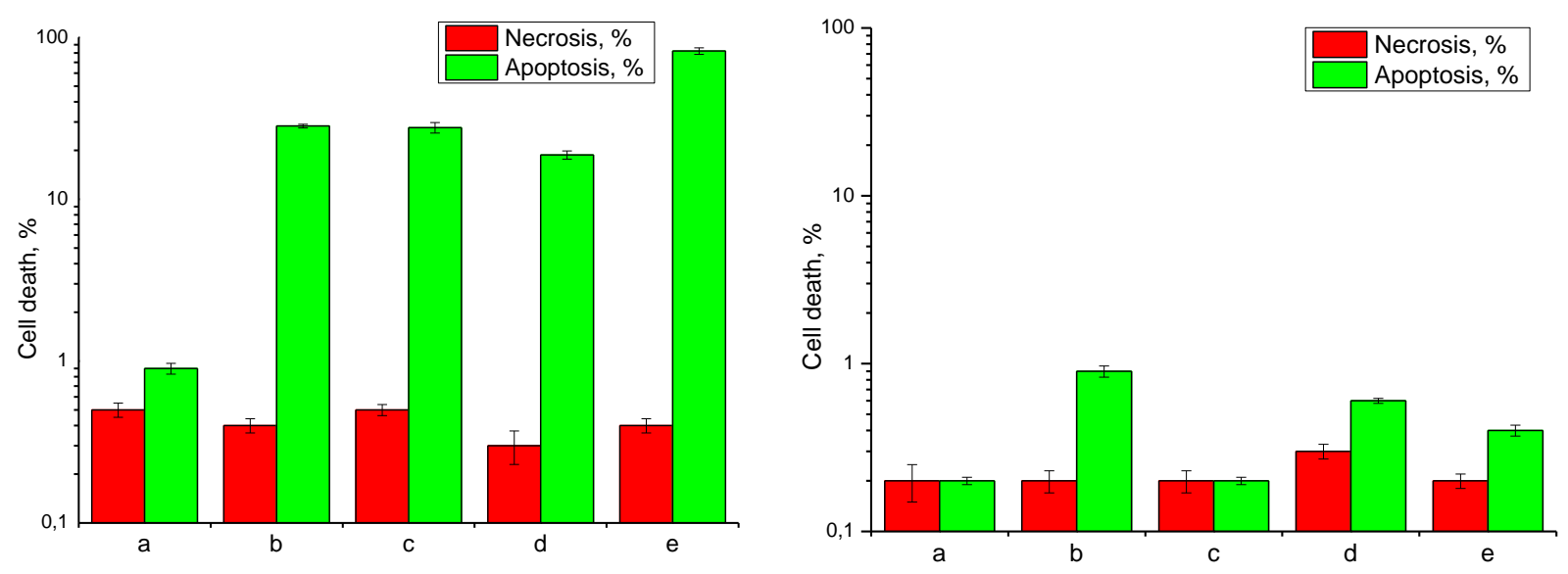

A549 line

MRC5 line

Figure 21. Effect of BDA and its composites with AG on viability of healthy MRC5 and cancer A549 lung cells: a) AG; b) BDA; c) BDA - AG (1:9, w/w) initial mixture; d) BDA - AG (1:9, w/w) mechanocomposite; e) BDA - AG composite as a film $(n=5, p<0,05)$.

In Figure 22, on the left, a comparison of the activity of betulin ester composites prepared by different methods is presented; on the right, there are some ideas about the mechanism of their activity. Interestingly, despite the high cytotoxicity of cancer cells, BDP and its composites did not influence healthy cells. The selectivity of betulin derivatives to cancer cells may be evoked by the intracellular reactive oxygen species (ROS) level, which is up to two times higher in malignant cells than in normal ones [53]. Betulin esters increase mitochondrial membrane permeability, multiplying ROS levels inside the cell. An increment of ROS content triggers apoptosis only in cancer cells because it reaches the threshold concentration. Thus, the mechanism of the antitumor effect of the studied substances is apparently similar to the mechanism of action of betulinic acid on cancer cells and is associated with an increase in mitochondrial permeability for reactive oxygen species. 


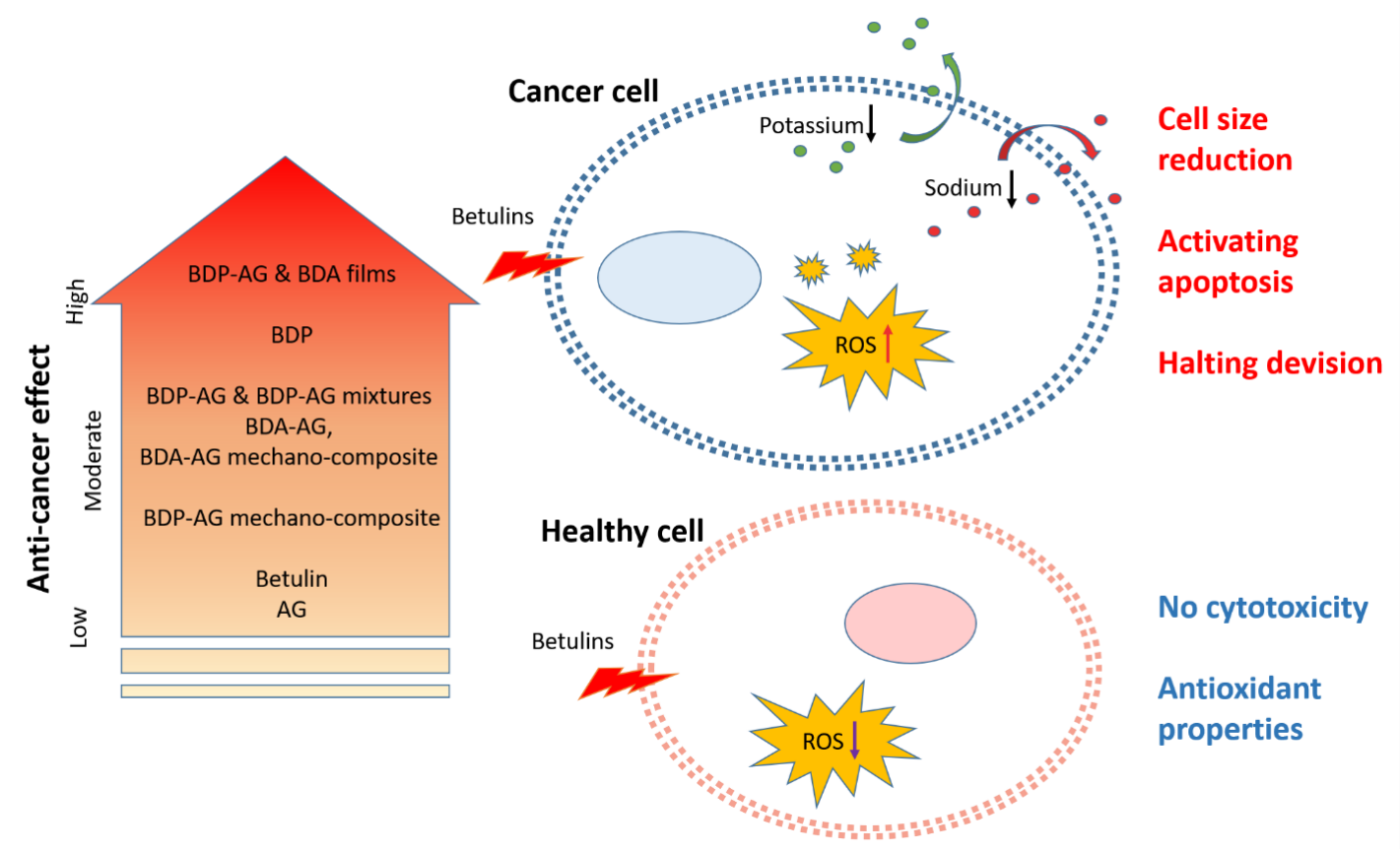

Figure 22. Schematic representation of a comparison of the effect of betulin and betulin ester derivatives on cancer cells and normal ones. Betulin ester derivatives selectively cause apoptosis and halted division in cancer cells and demonstrate antioxidant activities in normal ones.

\section{Conclusions}

The study results show that betulin dipropionate has a pronounced targeted antitumor effect on lung cancer cells, causing apoptosis in cancer cells and not affecting healthy cells. The one-step method for obtaining betulin dipropionate from birch bark and its physical and chemical properties are described.

In order to overcome inadequate solubility and availability of betulin dipropionate, various delivery systems based on the use of mechanochemical methods were suggested. Under ball-milling, the amorphous composite materials of betulin dipropionate with the excipients such as PVP, PEG, $\mathrm{SiO}_{2}$ characterized by an increased rate of dissolution in comparison with the initial BDP were obtained. Their pharmacological activity will deserve further study.

Powder composites of betulin dipropionate with water-soluble polysaccharide arabinogalactan showed higher solubility in comparison with the starting substance. Possible reasons for increased solubility are the disordering of crystal structures of the biologically active substance and the formation of molecular complexes with the polymer during mechanical activation. The composites of betulin ester with arabinogalactan were also prepared by dissolution of the physical or ball-milled mixtures of the components in water and subsequent solvent evaporation. These products were obtained as amorphous thin films readily soluble in water. The preparation of these completely water-soluble films can be very promising for use in pharmacy.

In vitro studies of anticancer activity of BDP - AG composite against human lung adenocarcinoma cells and against Ehrlich ascites carcinoma cells showed that the activity of the BDP composites prepared by different methods differs. Physical and ball-milled mixtures of BDP with AG exhibit lower antitumor activity than the initial substances. However, taking into account that the content of BDP in them is 10 times lower, their activity was 2-4 times higher than that of pure substance. Composites prepared as the water-soluble films possessed the highest anticancer activity. The studied composites showed a targeted antitumor effect, 
causing apoptosis in cancer cells without affecting healthy cells. Apparently, the mechanism of the action of BDP-AG composites on cancer cells is similar to betulinic acid and affects the mitochondrial function increasing their permeability to reactive oxygen species.

Finally, it should be noted that recently, the pharmacological activity, especially the antiviral activity of triterpenoids and betulin derivatives, in particular, has attracted the attention of researchers all over the world. At the same time, among the numerous derivatives of betulin, the most studied compounds were the derivatives of betulinic acid, while less attention was paid to the derivatives of betulin itself, for example, its esters. The results of this work show that betulin esters may be obtained without using complex synthetic methods and, in the development of adequate drug delivery systems, may turn out to be promising for use in pharmacology, having various pharmaceutically valuable properties. Investigation of their pharmacological activity is a challenge for future research.

\section{Funding}

This work was conducted within the framework of the budget project \#0287-2021-0017 for the Institute of Chemistry and Chemical Technology SB RAS, Institute of Solid State Chemistry and Mechanochemistry SB RAS (No. 1021052404489-6), and V.S. Sobolev Institute of Geology and Mineralogy SB RAS, using the equipment of Krasnoyarsk Regional Research Equipment Centre of SB RAS.

\section{Acknowledgments}

The authors are grateful to the Krasnoyarsk Regional Research Center of Equipment of the SB RAS for the physicochemical studies of the samples.

\section{Conflicts of Interest}

The authors declare no conflict of interest.

\section{References}

1. Amiri, S.; Dastghaib, S.; Ahmadi, M.; Mehrbod, P.; Khadem, F.; Behrouj, H.; Aghanoori, M.-R.; Machaj, F.; Ghamsari, M.; Rosik, J.; Hudecki, A.; Afkhami, A.; Hashemi, M.; Los, M.J.; Mokarram, P.; Madrakian, T.; Ghavami, S. Betulin and its derivatives as novel compounds with different pharmacological effects. Biotechnol Adv 2020, 38, 107409, https://doi.org/10.1016/j.biotechadv.2019.06.008.

2. Islam, M.T.; Sarkar, C.; El-Kersh, D.M.; Jamaddar, S.; Uddin, S.J.; Shilpi, J.A.; Mubarak, M.S. Natural products and their derivatives against coronavirus: A review of the non-clinical and pre-clinical data. Phytother Res 2020, 10, 2471-2492, https://doi.org/10.1002/ptr.6700.

3. Li, H; Sun, J; Xiao, S; Zhang, L; Zhou, D. Triterpenoid-mediated inhibition of virus-host interaction: Is now the time for discovering viral entry/release inhibitors from nature? J Med Chem 2020, 63, 24, 15371-15388, https://doi.org/10.1021/acs.jmedchem.0c01348.

4. Xiao, S.; Tian, Z.; Wang, Y.; Si, L.; Zhang, L.; Zhou, D. Recent progress in the antiviral activity and mechanism study of pentacyclic triterpenoids and their derivatives. Med Res Rev 2018, 38, 951-976, https://doi.org/10.1002/med.21484.

5. Liu, K; Zhang, X; Xie, L; Deng, M; Chen, H; Song, J; Long, J; Li, X; Luo, J. Lupeol and its derivatives as anticancer and anti-inflammatory agents: Molecular mechanisms and therapeutic efficacy. Pharmacol Res 2021, 164, 105363, https://doi.org/10.1016/j.phrs.2020.105373.

6. Hordyjewska, A.; Ostapiuk, A.; Horecka, A; Kurzepa J. Betulin and betulinic acid: Triterpenoids derivatives with a powerful biological potential. Phytochem Rev 2019, 18, 929-951, https://doi.org/10.1007/s11101-01909623-1.

7. Lombrea, A.; Scurtu, A.D.; Avram, S.; Pavel, I.Z.; Turks, M.; Lugininina, J.; Peipiņš, U.; Dehelean, C.A.; Soica, C.; Danciu, C. Anticancer potential of betulonic acid derivatives. Int J Mol Sci 2021, 22, 3676, https://doi.org/10.3390/ijms22073676. 
8. El-Baba, C.; Baassiri, A.; Kiriako, G; Dia, B.; Fadlallah, S.; Moodad, S.; Darwiche, N. Terpenoids' anticancer effects: focus on autophagy. Apoptosis 2021, 26, 491-511, https://doi.org/10.1007/s10495-021-01684-y.

9. Zhong, Y; Liang, N; Liu, Y; Cheng, MS. Recent progress on betulinic acid and its derivatives as antitumor agents: a mini review. Chin J Natur Med 2021, 19, 641-647 https://doi.org/10.1016/S1875-5364(21)600973.

10. Lombrea, A.; Scurtu, A.D.; Avram, S.; Pavel, I.Z.; Turks, M.; Lugininina, J.; Peipiņš, U.; Dehelean, C.A.; Soica, C.; Danciu, C. Anticancer potential of betulonic acid derivatives. Int J Mol Sci. 2021 22, 3676, https://doi.org/10.3390/ijms22073676.

11. Mukherjee, B.; Al Hoque, A.; Dutta, D.; Paul, B.; Mukherjee, A; Mallick, S. Nanoformulated drug delivery of potential betulinic acid derivatives: A promising approach toward cancer therapy. In Nanomedicine fot Bioactives; Rahman, M.; Beg, S.; Kumar, V., Ahmad, F., Eds.; Springer: Singapore 2020, https://doi.org/10.1007/978-981-15-1664-1_4.

12. Król, S.K.; Bębenek, E; Sławińska-Brych, A; Dmoszyńska-Graniczka, M; Boryczka, S; Stepulak, A. Synthetic betulin derivatives inhibit growth of glioma cells in vitro. Anticancer Res 2020, 40, 11, 6151-6158, https://doi.org/10.21873/anticanres.14635. PMID: 33109552.

13. Mierina, I; Vilskersts, R.; Turks, M. Delivery systems for birch-bark triterpenoids and their derivatives in anticancer research. Curr Med Chem 2020, 27, 1308-1336, https://doi.org/10.2174/0929867325666180530095657.

14. Lucas, S.; Omata, Y.; Hofmann, J.; Böttcher, M.; Iljazovic, A.; Sarter, K.; Albrecht, O.; Schulz, O.; Krishnacoumar, B.; Krönke, G.; Herrmann, M.; Mougiakakos, D.; Strowig, T.; Schett, G.; Zaiss, M.M. Shortchain fatty acids regulate systemic bone mass and protect from pathological bone loss. Nat Commun 2018, 9 , 55, https://doi.org/10.1038/s41467-017-02490-4.

15. Fan, Y.; Pedersen, O. Gut microbiota in human metabolic health and disease. Nat Rev Microbiol. 2021, 19, 55-71, https://doi:10.1038/s41579-020-0433-9.

16. Scheiman, J.; Luber, J.; Chavkin, T.; Macdonald, T.; Tung, A.; Pham, L.-D.; Wibowo, M.; Wurth, R.; Punthambaker, S.; Tierney, B.; Yang, Z.; Hattab, M.; Avila, J.; Clish, C.; Lessard, S.; Church, G.; Kostic, A. Meta-omics analysis of elite athletes identifies a performance-enhancing microbe that functions via lactate metabolism. Nat Med 2019, 25, 1104-1109, https://doi.org/10.1038/s41591-019-0485-4.

17. Ashaolu, T.J.; Ashaolu, J.O.; Adeyeye, S.A.O. Fermentation of prebiotics by human colonic microbiota in vitro and short-chain fatty acids production: a critical review. J Applied Microbiol 2021, 130, 3, 677-683, https://doi.org/10.1111/jam.14843.

18. Pobeguts, O.V.; Ladygina, V.G.; Evsyutina, D.V.; Eremeev, A.V.; Zubov, A.I.; Matyushkina, D.S.; Scherbakov, P.L.; Rakitina, D.V.; Fisunov, G.Y. Propionate induces virulent properties of Crohn's DiseaseAssociated Escherichia coli. Front Microbiol 2020, 11, 1460, https://doi.org/10.3389/fmicb.2020.01460.

19. Bachořík, J.; Urban, M. Biocatalysis in the chemistry of lupane triterpenoids. Molecules 2021, 26, 2271, https://doi.org/10.3390/molecules26082271.

20. Shakhtshneider, T.P.; Boldyrev, V.V. Mechanochemical synthesis and mechanical activation of drugs. In Reactivity of Molecular Solids. Boldyreva, E., Boldyrev, V., Eds.; John Wiley \& Sons, LTD: England 1999, 271-312, ISBN 0-471-99907-5.

21. Friscic, T.; Mottillo, C.; Titi, H.M. Mechanochemistry for synthesis. Angew Chem Int Ed 2020, 59,10181029, https://doi.org/10.1002/anie.201906755.

22. Bose, A.; Mal, P. Mechanochemistry of supramolecules. Beilstein J Org Chem 2019, 15, 881-900, https://doi.org/10.3762/bjoc.15.86.

23. Bray, F.; Ferlay, J.; Soerjomataram, I.; Siegel, R.L.; Torre, L.A.; Jemal, A. Global cancer statistics 2018: GLOBOCAN estimates of incidence and mortality worldwide for 36 cancers in 185 countries. CA Cancer J Clin 2018, 68, 394-424, https://doi.org/10.3322/caac.21492.

24. Kuznetsova, S.A.; Skvortsova, G.P.; Malyar, Yu.N.; Sokolenko, V.A.; Kuznetsov, B.N. Synthesis of the betulin dipropionate from the upper birch bark. Russ J Bioorganic Chem 2012, 38, 743-748, https://doi.org/10.1134/S1068162012070126.

25. Kuznetsova, S.A.; Kuznetsov, B.N.; Mikhailov, A.G.; Skvortsova, G.P. Method of obtaining arabinogalactan. Patent RF 2273646 2006, Apr 10.

26. Kuznetsova, S.A.; Shakhtshneider, T.P.; Mikhailenko, M.A.; Malyar, Yu.N.; Zamay, A.S.; Boldyrev, V.V. Obtaining mechanocomposites of betulin diacetate with arabinogalactan and studying their antitumor properties. J Siber Federal Univ Chem 2013, 6, 192-202.

27. Shakhtshneider, T.P.; Kuznetsova, S.A.; Zamay A.S.; Zamay, T.N.; Spivak, E.A.; Mikhailenko, M.A.; Malyar, Yu.N.; Kuznetsov, B.N.; Chesnokov, N.V.; Boldyrev, V.V. New composites of betulin esters with arabinogalactan as highly potent anticancer agents. Nat Prod Res 2016, 30, 1382-1387, http://dx.doi.org/10.1080/14786419.2015.1060591.

28. Kuznetsova, S.A.; Shakhtshneider, T.P.; Mikhailenko, M.A.; Malyar, Yu.N.; Spivak, E.A.; Zamai, T.N.; Zamai, A.S.; Chesnokov, N.V.; Kuznetsov, B.N.; Boldyrev V.V. Antitumor activity of the diacylated betulin composites with arabinogalactan. Dokl Chem 2014, 459, 199-201, https://doi.org/10.1134/S0012500814110019. 
29. Kuznetsova, S.A.; Pen, R.Z.; Kuznetsov, B.N. Optimization of the process of obtaining biologically active betulin dipropionate from birch bark. Chem Plant Raw Mater 2021, 1, 309-316, https://doi.org/10.14258/jcprm.2021017973.

30. Levdansky, V.A.; Kondrasenko, A.A.; Levdansky, A.V.; Kuznetsov, B.N. Synthesis of betulin diacetate and betulin dipropionate. J Siber Federal Univ Chem 2016, 9, 337-344, https://doi.org/10.17516/1998-28362016-9-3-337-344.

31. Drebushchak, V.A.; Mikhailenko, M.A.; Shakhtshneider, T.P.; Drebushchak, T.N.; Kuznetsova, S.A.; Malyar, Yu.N. Thermal properties of betulin dipropionate and its mixtures with polymers. J Therm Anal Calorim 2014, 115, 2521-2525, https://doi.org/10.1007/s10973-013-3578-1.

32. Drebushchak, T.N.; Mikhailovskaya, A.V.; Drebushchak, V.A.; Mikhailenko, M.A.; Myz, S.A.; Shakhtshneider, T.P.; Kuznetsova, S.A. Crystal forms of betulin. Polymorphism or pseudopolymorphism? J Struct Chem 2020, 61, 1260-1266, https://doi.org/10.1134/S0022476620080119.

33. Mikhailenko, M.A.; Drebushchak, V.A.; Kuznetsova, S.A.; Skvortsova, G.P.; Boldyrev, V.V. Influence of mechanical treatment on the properties of betulin, betulin diacetate, and their mixture with water-soluble polymers. Chem Nat Compd 2011, 47, 229-233, https://doi.org/10.1007/s10600-011-9889-1.

34. Franco, P.; De Marco, I. Supercritical antisolvent coprecipitation in the pharmaceutical field: Different polymeric carriers for different drug releases. Can J Chem Eng 2020, 98, 1935-1943, https://doi.org/10.1002/cjce.23759.

35. Chen, X.; Partheniadis, I.; Nikolakakis, I.; Al-Obaidi, H. Solubility Improvement of progesterone from solid dispersions prepared by solvent evaporation and co-milling. Polymers 2020, 12, 854, https://doi.org/10.3390/polym12040854.

36. Kuznetsova, S.A.; Mikhailenko, M.A.; Shakhtshneider T.P.; Malyar, Yu.N.; Skvortsova, G.P.; Veselova, O.F.; Boldyrev, V.V. Betulin composites and their antiulcer properties. In Proceedings of International Conference "Renewable Wood and Plant Resourses: Chemistry, Technology, Pharmacology, Medicine", Saint-Petersburg, Russia, June 21-24, 2011, 118-119.

37. Shakhtshneider, T.P.; Kuznetsova, S.A.; Mikhailenko, M.A.; Zamay, T.N.; Malyar, Yu.N.; Skvortsova, G.P.; Boldyrev, V.V. Development of an antitumor agent based on composites of betulin with polymers. In Proceedings of V All-Russian conference with international participation "New achievements in the chemistry and chemical technology of plant raw materials", Barnaul, Russia, April 24-26, 2012, 174-176.

38. Kuznetsova, S.A.; Mikhailenko, M.A.; Shakhtshneider T.P.; Malyar, Yu.N.; Veselova, O.F.; Zamay, T.N.; Boldyrev, V.V. Antitumor effect of betulin and its composites. In Proceedings of All-Russian scientific and practical conference with international participation "Scientific and practical aspects of modernization of the regional oncological service", Krasnoyarsk, Russia, May 24-25, 2012, 99-105.

39. Dong, C.L.; Zheng, S.D.; Liu, Y.Y.; Cui, W.Q.; Hao, M.Q.; God'spower, B.O.; Chen, X.Y.; Li, Y.H. Albendazole solid dispersions prepared using PEG 6000 and Poloxamer 188: formulation, characterization and in vivo evaluation. Pharm Dev Technol 2020, 25, 1043-1052, https://doi.org/10.1080/10837450.2020.1783553.

40. d'Avanzo, N.; Celia, C.; Barone, A.; Carafa, M.; Di Marzio, L.; Santos, H.A.; Fresta, M. Immunogenicity of polyethylene glycol based nanomedicines: Mechanisms, clinical implications and systematic approach. Adv Therap 2020, 3, 1900170, https://doi.org/10.1002/adtp.201900170.

41. Shakhtshneider, T.P.; Mikhailenko, M.A.; Drebushchak, V.A.; Drebushchak, T.N.; Malyar, Yu.N.; Kuznetsova, S.A. Effect of ball-milling on the formation of betulin and betulin diacetate composites with polyethylene glycol. Mater Today: Proceed 2019, 12, 78-81, https://doi.org/10.1016/j.matpr.2019.03.068.

42. Veselova, O.F.; Gaydash, A.A.; Okladnikova, E.V.; Kuznetsova, S.A.; Shakhtshneider T.P.; Storozhenko S.E. Active betulin and its composites with polyethylene glycol in models of acute renal failure in rats. Modern Problems of Science and Education 2015, 4, 456.

43. Tang, S.; Wang, T.; Huang, C.; Lai, C.; Fan, Y.; Yong, Q. Arabinogalactans from Larix principis-rupprechtii: An investigation into the structure-function contribution of side-chain structures. Carbohydr Polym 2020, 115354, 227, https://doi.org/10.1016/j.carbpol.2019.115354.

44. Singh, B.; Kumar, A. Exploration of arabinogalactan of gum polysaccharide potential in hydrogel formation and controlled drug delivery applications. Int J Biol Macromol 2020, 147, 482-492, https://doi.org/10.1016/j.ijbiomac.2020.01.087.

45. De, A.; Das, B.; Mitra, D.; Sen, K.A.; Samanta, A. Exploration of an arabinogalactan isolated from Odina wodier Roxb.: Physicochemical, compositional characterisations and functional attributes. Polym Adv Technol 2020, 1814-1826, 31, https://doi.org/10.1002/pat.4908.

46. Gong, G; Liu, Q; Deng, Y; Dang, T; Dai, W; Liu,T; Liu, Y; Sun, J; Wang, L; Liu, Y; Sun, T; Song, S; Wang, Z; Huang, L. Arabinogalactan derived from Lycium barbarum fruit inhibits cancer cell growth via cell cycle arrest and apoptosis. Int J Biol Macromol https://doi.org/10.1016/j.ijbiomac.2020.01.251.

47. Dushkin, A.V.; Meteleva, E.S.; Tolstikova, T.G.; Tolstikov, G.A.; Polyakov, N.E.; Neverova, N.A.; Medvedeva, E.N.; Babkin, V.A. Mechanochemical preparation and pharmacological activities of watersoluble intermolecular complexes of arabinogalactan with medicinal agents Russ Chem Bull 2008, 57, 12991307, https://doi.org/10.1007/s11172-008-0167-8. 
48. Shakhtshneider, T.P.; Kuznetsova, S.A.; Mikhailenko, M.A.; Zamai, A.S.; Malyar, Y.N.; Zamai, T.N.; Boldyrev V.V. Effect of mechanochemical treatment on physicochemical and antitumor properties of betulin diacetate mixtures with arabinogalactan. Chem Nat Compd 2013, 49, 470-474, https://doi.org/10.1007/s10600-013-0641-X.

49. Magro, M.; Venerando, A.; Macone, A.; Canettieri, G.; Agostinelli, E.; Vianello, F. Nanotechnology-based strategies to develop new anticancer therapies. Biomolecules 2020, 10, 735, https://doi.org/10.3390/biom10050735.

50. Malyar, Y.N.; Kuznetsova, S.A.; Shakhtshneider, T.P.; Mikhailenko, M.A. Obtaining of betulin diacetate and betulin dipropionate composites with aerosil. Journal of Siberian Federal University-Chemistry 2015, 8, 277286, https://doi.org/10.17516/1998-2836-2015-8-2-277-286.

51. Hordyjewska, A.; Ostapiuk, A.; Horecka, A. Betulin and betulinic acid in cancer research. J Pre Clin Clin Res 2018, 12, 72-75, https://doi.org/10.26444/jpccr/92743.

52. Yao, N.; Wang, C.; Hu, N.; Li, Y.; Liu, M.; Lei, Y.; Chen, M.; Chen, L.; Chen, C.; Lan, P.; Chen, W.; Chen, Z.; Fu, D.; Ye, W.; Zhang, D. Inhibition of PINK1/Parkin-dependent mitophagy sensitizes multidrug-resistant cancer cells to B5G1, a new betulinic acid analog. Cell Death Dis 2019, 10, 232, https://doi.org/10.1038/s41419-019-1470-z.

53. Coricovac, D.; Dehelean, C.A.; Pinzaru, I.; Mioc, A.; Aburel, O.-M.; Macasoi, I.; Draghici, G.A.; Petean, C.; Soica, C.; Boruga, M.; Vlaicu, B.; Muntean, M.D. Assessment of betulinic acid cytotoxicity and mitochondrial metabolism impairment in a human melanoma cell line. Int J Mol Sci 2021, 22, 4870, https://doi.org/10.3390/ijms22094870.

54. Zanon, M.; Piris, A.; Bersani, I.; Vegetti, C.; Molla, A.; Scarito A.; Anichini, A. Apoptosis protease activator protein-1 expression is dispensable for response of human melanoma cells to distinct proapoptotic agents. Cancer Res 2004, 64, 20, 7386-7394, https://doi.org/10.1158/0008-5472.CAN-04-1640.

55. Orchel, A.; Chodurek, E.; Jaworska-Kik, M.; Paduszyński, P.; Kaps, A.; Chrobak, E.; Bębenek, E.; Boryczka, S.; Borkowska, P.; Kasperczyk, J. Anticancer activity of the acetylenic derivative of betulin phosphate involves induction of necrotic-like death in breast cancer cells in vitro. Molecules 2021, 26, 615, https://doi.org/10.3390/molecules26030615.

56. Kasperczyk, H.; La Ferla-Brühl, K.; Westhoff, M.A.; Behrend, L.; Zwacka, R.M.; Debatin, K.M.; Fulda, S. Betulinic acid as new activator of NF- $\mathrm{BB}$ : molecular mechanisms and implications for cancer therapy. Oncogene 2005, 24, 6945-6956, https://doi.org/10.1038/sj.onc.1208842.

57. Zuco, V.; Supino, R.; Righetti, S.C.; Cleris, L.; Marchesi, E.; Gambacorti-Passerini, C.; Formelli, F. Selective cytotoxicity of betulinic acid on tumor cell lines, but not on normal cells. Cancer Lett 2002, 175, 17-25, https://doi.org/10.1016/s0304-3835(01)00718-2.

58. Günther, A.; Makuch, E.; Nowak, A.; Duchnik, W.; Kucharski, Ł.; Pełech, R.; Klimowicz, A. Enhancement of the antioxidant and skin permeation properties of betulin and its derivatives. Molecules 2021, 26, 3435, https://doi.org/10.3390/molecules26113435.

59. Zhang, W.; Jiang, H.; Yang, J.; Jin, M.; Du, Y.; Sun, Q.; Cao, L.; Xu, H. Safety assessment and antioxidant evaluation of betulin by LC-MS combined with free radical assays. Anal Biochem 2019 587, 113460. https://doi.org/10.1016/j.ab.2019.113460.

60. Park, C.; Jeong, J.W.; Han, M.H.; Lee H.; Kim G.Y.; Jin S.; Park J.H.; Kwon H.J.; Kim B.W.; Choi Y.H. The anticancer effect of betulinic acid in u937 human leukemia cells is mediated through ROS-dependent cell cycle arrest and apoptosis. Animal Cells Systems 2021, 25, 119-127, https://doi.org/10.1080/19768354.2021.1915380.

61. Rijo, P.; Pešić, M.; Fernandes, A.S.; Santos, C.N. Natural products: optimizing cancer treatment through modulation of redox balance. Oxid Med Cell Longev 2020, 2407074, https://doi.org/10.1155/2020/2407074.

62. Drąg-Zalesińska, M.; Borska, S. Betulin and its derivatives - precursors of new drugs. World Scientific News 2019, 127, 3, 123-138.

63. Kuznetsova, S.A.; Shakhtshneider, T.P.; Mikhailenko, M.A.; Malyar, Y.N.; Boldyrev V.V. Composition on the base of betulin dipropionate. Patent $R F$ 2541153. 2015, Feb 10. 